NBER WORKING PAPER SERIES

\title{
IMPORTING SKILL-BIASED TECHNOLOGY
}

\author{
Ariel Burstein \\ Javier Cravino \\ Jonathan Vogel \\ Working Paper 17460 \\ http://www.nber.org/papers/w17460
NATIONAL BUREAU OF ECONOMIC RESEARCH
1050 Massachusetts Avenue
Cambridge, MA 02138
September 2011

We thank Andrew Atkeson and Arnaud Costinot for helpful suggestions, David Autor, Francisco Gallego, and Pedro Silos for kindly making their data available to us, and the National Science Foundation (under Grant SES-0962261) for research support. Any opinions, findings, and conclusions or recommendations expressed in this paper are those of the authors and do not necessarily reflect the views of the National Science Foundation, the National Bureau of Economic Research, or any other organization.

NBER working papers are circulated for discussion and comment purposes. They have not been peerreviewed or been subject to the review by the NBER Board of Directors that accompanies official NBER publications.

(C) 2011 by Ariel Burstein, Javier Cravino, and Jonathan Vogel. All rights reserved. Short sections of text, not to exceed two paragraphs, may be quoted without explicit permission provided that full credit, including $\odot$ notice, is given to the source. 
Importing Skill-Biased Technology

Ariel Burstein, Javier Cravino, and Jonathan Vogel

NBER Working Paper No. 17460

September 2011

JEL No. F1

\section{ABSTRACT}

Capital equipment - such as computers and industrial machinery - embodies skill-biased technology, in the sense that it is complementary to skilled labor. Most countries import a large share of their capital equipment, and by doing so import skill-biased technology. In this paper we develop a tractable quantitative model of international trade in capital goods to quantify the extent to which trade, through capital-skill complementarity, raises the relative demand for skill and hence increases the skill premium. In one counterfactual, we find that moving from the trade levels observed in the year 2000 to autarky would decrease the skill premium by $16 \%$ in the median country in our sample, by $5 \%$ in the US, and by a much larger magnitude in countries that heavily rely on imported capital equipment.

Ariel Burstein

Department of Economics

Bunche Hall 8365

Box 951477

UCLA

Los Angeles, CA 90095-1477

and NBER

arielb@econ.ucla.edu

Javier Cravino

Department of Economics

UCLA

Bunche Hall 8365

Los Angeles, CA 90095-1477

jcravino@ucla.edu
Jonathan Vogel

Department of Economics

Columbia University

420 West 118th Street

New York, NY 10027

and NBER

jvogel@columbia.edu 


\section{Introduction}

Capital equipment - such as computers and industrial machinery-embodies skill-biased technology, in the sense that it is complementary to skilled labor. ${ }^{1}$ It is also highly traded, with production concentrated among a small group of countries; see e.g. Eaton and Kortum (2001). ${ }^{2}$ Many countries import a large share of their capital equipment, ${ }^{3}$ and by doing so import skill-biased technology. In this paper we develop a model of international trade and capital-skill complementarity to quantify the extent to which trade raises the relative demand for skill, and hence increases the skill premium (the wage of skilled labor relative to unskilled labor) in a range of countries.

We use a multi-country Ricardian model-following Eaton and Kortum (2002) (henceforth EK) — extended to allow for capital-skill complementarity - following Krusell, Ohanian, Rios-Rull, and Violante (2000) (henceforth KORV). ${ }^{4}$ With capital-skill complementarity, an increase in the stock of capital equipment tends to raise the demand for skilled relative to unskilled labor. With international trade, the aggregate stock of capital equipment in one country depends on all foreign productivities and labor endowments, and on the trade costs between every pair of countries. We show, however, that changes in trade costs, foreign productivities, and foreign labor endowments affect a country's steady-state stock of capital equipment only through changes in its domestic sectoral expenditure shares, i.e., the share of its sectoral absorption that is produced domestically. ${ }^{5}$ Hence, steady-state changes in a country's skill premium are determined by changes in its domestic expenditure share in each sector, domestic productivity in each sector, and domestic labor endowments.

Using this insight, we offer a simple analytic expression for the steady-state change in the skill premium, to a first-order approximation, which makes transparent the qualitative and quantitative effects on the skill premium of changing trade patterns, domestic productivities, and domestic labor endowments. Three parameters are key in shaping the mapping from

\footnotetext{
${ }^{1}$ Since Griliches (1969), various empirical papers provide support for this hypothesis; see e.g. Katz and Autor (1999), who summarize the literature documenting a positive correlation between the use of computerbased technologies and employment of skilled labor within industries, firms, and plants.

${ }^{2}$ For example, $80 \%$ of the world's capital equipment production occurred in just eight countries in the year 2000: the U.S., Japan, Germany, China, France, Korea, the U.K., and Italy. Source: Unido Industrial Statistics.

${ }^{3}$ For example, the share of domestic absorption imported from abroad in the equipment sector in the year 2000 was $73 \%$ in the U.K., $81 \%$ in Australia, $84 \%$ in Chile, and $96 \%$ in Cameroon. Source: our calculation using trade data from Feenstra et. al. (2005) and Unido Industrial Statistics.

${ }^{4}$ See e.g. Polgreen and Silos (2008) and Jaimovich, Pruitt, and Siu (2010) for other macroeconomic applications of capital-skill complementarity.

${ }^{5}$ Here, we apply the insight of EK and Arkolakis, Costinot, and Rodriguez-Clare (Forthcoming), who show that - across a wide range of workhorse frameworks - the impact on domestic welfare (i.e. the stock of domestic consumption) of foreign technological change and changes in trade costs are trasmitted only through changes in domestic expenditure shares.
} 
changes in the pattern and volume of international trade to changes in the skill premium: the dispersion of productivities within sectors, which determines the elasticity of trade with respect to trade costs, and two production function elasticities, which together determine the extent of capital-skill complementarity and the elasticity of substitution between skilled and unskilled labor. While the dispersion of productivities within sectors is a standard parameter in Ricardian models of trade, the production function elasticities are not. Hence, we pursue several strategies to parameterize these using structural equations delivered by the model. We both calibrate and estimate these elasticities using US data on changes between 1963 and 2000 in factor shares and factor supplies, in each case finding a significant degree of capital-skill complementarity. In order to assess the degree of capital-skill complementarity in a developing country that is a net importer of capital equipment, we also estimate the elasticities using Chilean data between 1974 and 2000 and obtain very similar results.

We use our parameterized model to quantify the impact of changing trade flows on the skill premium through capital-skill complementarity. We conduct two counterfactuals. In the first, we determine how much each country's skill premium would change if it were moved to autarky. In the second, we determine the impact of changes in observed trade flows on each country's skill premium. Through these counterfactuals, we are interested in addressing the extent to which countries may import a rise in the skill premium. We are not directly concerned with whether a change in trade patterns is driven by changing technologies, labor endowments, or trade costs.

These counterfactuals exploit the simple structure of our model, which allows us to conduct these exercises country-by-country because the impact of changes in any foreign technology, foreign labor endowment, or any trade cost is transmitted only through changes in domestic expenditure shares. By taking changes in trade flows as given, we are able to conduct each counterfactual without actually computing the model's full multi-country general equilibrium. We find that international trade plays an important role in shaping the skill premium, but that its importance varies widely across countries in our sample. For example, moving from the trade levels observed in the year 2000 to autarky would imply a decrease in the skill premium of $16 \%$ for the median country in our sample. The decrease is relatively small in the US $(5 \%)$, which has a comparative advantage in capital equipment, and is much larger in countries that rely heavily on imports for their capital equipment, including developed countries such as Canada (25\%) and developing countries such as Chile (20\%). In addition, observed changes in trade flows over the last few decades generate large increases in the skill premium in various countries, especially those with a large increase in equipment imports. For instance, we find that if the UK and Canada return to their 1963 trade levels, the skill premium in these countries would decrease by $13 \%$ and $19 \%$ 
respectively. On the other hand, in the US the counterfactual decrease in the skill premium would be only $5 \%$.

Our paper builds on a growing literature empirically documenting the impact of international trade on technological change see e.g. Pavcnik (2002), De Loeker (2010), Lileeva and Trefler (2010), and Bustos (2011a) — and on the skill intensity of production - see e.g. Verhoogen (2008), Bloom, Draca, and Van Reenen (2011), Bustos (2011b), and Koren and Csillag (2011) — using detailed firm, plant, and sector-level data. These papers provide empirical support for the hypothesis that international trade can generate skill-biased technological change, as posited by, e.g., Acemoglu (2003), Thoenig and Verdier (2003), and Yeaple (2005). While some of these empirical papers study the implications for the skill intensity of production of increased export-market access or import competition, our paper is most closely related to Koren and Csillag (2011), who study the firm-level link between capital imports and wages. Our contribution is to embed a mechanism studied in these papers into a quantitative general equilibrium trade model.

Our paper is most closely related to Parro (2010), who uses a similar model that incorporates capital-skill complementarity and the Stolper-Samuelson effect to study the impact of trade on the skill premium. ${ }^{6}$ There are three main differences between these two papers. First, we abstract from the Stolper-Samuelson effect. Second, we provide a simple expression for the elasticity of a country's skill premium with respect to each sector's domestic productivity and domestic expenditure share, which does not depend on changes in trade costs, foreign productivities, foreign labor endowments, or trade shares in other countries. Third, the counterfactuals that we perform are different: whereas we study the overall impact of given changes in trade patterns on the skill premium by exploiting the simple structure of the equilibrium of the model, Parro studies the impact of changing worldwide trade costs and technologies on the skill premium by estimating changes in trade costs and technologies. ${ }^{7}$

\section{The Model}

Overview: We consider a world economy featuring $I$ countries, indexed by $i=1, . ., I$. Within each country, a representative household acquires utility from consumption of manufactured goods and services. Each country is endowed with $H_{i}$ and $L_{i}$ efficiency units of

\footnotetext{
${ }^{6}$ For an earlier theoretical treatment of trade in skill-complementary capital in a neo-classical growth model, see Stokey (1996).

${ }^{7}$ Another related paper is Burstein and Vogel (2010), which studies the impact of international trade and multinational production on the skill premium, with special emphasis on the U.S., arising from two mechanisms from which we abstract: $(i)$ the Stolper-Samuelson effect and (ii) within-sector factor reallocation in the presence of skill-biased productivity.
} 
skilled and unskilled labor, respectively. Heterogeneous producers of intermediate goods use labor in combination with capital equipment, capital structures, and intermediate inputs. To incorporate capital-skill complementarity, we allow for the elasticity of substitution between skilled labor and capital equipment to differ from that between unskilled labor and equipment.

Producers differ in terms of productivity and the sector in which they produce. There are three sectors, indexed by $j$ : $(i)$ a manufacturing sector, $j=M$, whose firms produce tradable goods that are used for consumption and as intermediate inputs; (ii) a service sector, $j=S$, whose firms produce non-tradable goods that are used for consumption, intermediate inputs, and investment in structures; and (iii) a capital equipment sector, $j=E$, whose firms produce tradable goods that are used for investment in capital equipment. Tradable goods are subject to variable iceberg international trade costs. All labor and goods markets are perfectly competitive. To simplify the notation, but without loss of generality for our results on the impact of trade on the skill premium, we abstract from trend-growth in sector-specific or factor-specific productivities.

Preferences: Utility of the representative household is given by

$$
\sum_{t=0}^{\infty} \beta^{t} u\left(C_{i, t}(M)^{\phi} C_{i, t}(S)^{1-\phi}\right)
$$

where $C_{i, t}(M)$ and $C_{i, t}(S)$ denote consumption of manufactured goods and services, respectively, $u($.$) is a concave sub-utility function defined over aggregate consumption, \phi \in[0,1]$ is the share of manufactured goods in consumption, and $\beta \in(0,1)$ is the discount rate. The household's budget constraint equates consumption and investment expenditures (investment is discussed below) with labor income, payments to capital, and the value of net exports. Given that our steady-state results do not depend on the value of the trade balance, we do not make assumptions on the availability of international financial assets. Given that we focus our attention on steady-state equilibria, in what follows we mostly abstract from time subscripts.

Sectoral output: Sector $j$ uses a continuum of intermediate goods, each indexed by $\omega \in$ $[0,1]$, according to a CES production function with country- and sector-specific elasticity of substitution $\eta_{i}(j)>1$,

$$
Y_{i}(j)=\left\{\int_{0}^{1} q_{i}(\omega, j)^{\left[\eta_{i}(j)-1\right] / \eta_{i}(j)} d \omega\right\}^{\eta_{i}(j) /\left[\eta_{i}(j)-1\right]}
$$

where $q_{i}(\omega, j)$ is consumption of intermediate good $(\omega, j)$ in country $i$. Each intermediate 
$\operatorname{good}(\omega, j)$ is potentially produced in every country.

Output from the manufacturing sector can be used for consumption, $C_{i}(M)$, and intermediate inputs, $X_{i}(M)$ :

$$
Y_{i}(M)=C_{i}(M)+X_{i}(M)
$$

Output from the service sector can be used for consumption, $C_{i}(S)$, intermediate inputs, $X_{i}(S)$, and structures investment, $I_{i}(S)$ :

$$
Y_{i}(S)=C_{i}(S)+X_{i}(S)+I_{i}(S)
$$

Output from the equipment sector is used only for equipment investment, $I_{i}(E)$ :

$$
Y_{i}(E)=I_{i}(E)
$$

The aggregate law of motion of structures and equipment is

$$
K_{i, t+1}(j)=\left[1-\delta_{i}(j)\right] K_{i, t}(j)+I_{i, t}(j), \text { for } j=S, E,
$$

where we have re-introduced time subscripts to indicate the dynamics, and where $\delta_{i}(j) \in$ $(0,1)$ is the depreciation rate of capital of type $j=S, E$ in country $i$.

Production of intermediate goods: All producers of intermediate good $(\omega, j)$ in country $i$ produce according to the following constant returns to scale production function:

$$
\begin{aligned}
y_{i}(\omega, j)= & A_{i}(j) z_{i}(\omega, j)\left(x_{S}^{\varepsilon_{i}} x_{M}^{1-\varepsilon_{i}}\right)^{1-\zeta_{i}} k_{S}^{\alpha_{i} \zeta_{i}} \times \\
& \left\{\mu_{i}^{\frac{1}{\sigma}} l^{\frac{\sigma-1}{\sigma}}+\left(1-\mu_{i}\right)^{\frac{1}{\sigma}}\left[\lambda_{i}^{\frac{1}{\rho}} k_{E}^{\frac{\rho-1}{\rho}}+\left(1-\lambda_{i}\right)^{\frac{1}{\rho}} h^{\frac{\rho-1}{\rho}}\right]^{\frac{\rho(\sigma-1)}{(\rho-1) \sigma}}\right\}^{\frac{\sigma\left(1-\alpha_{i}\right) \zeta_{i}}{\sigma-1}}
\end{aligned}
$$

Producers combine intermediate inputs (of services, $x_{S}$, and manufactured goods, $x_{M}$ ) with structures, $k_{S}$, capital equipment, $k_{E}$, unskilled labor, $l$, and skilled labor $h$. The share of value added in gross output is given by $\zeta_{i}$. As discussed in more detail below, the parameters $\sigma$ and $\rho$ determine the elasticities of substitution between capital equipment, unskilled labor, and skilled labor. A low value of $\rho$ relative to $\sigma$ implies that capital equipment is less substitutable with skilled labor than with unskilled labor. In particular, when $\sigma>\rho$ the production function exhibits capital-skill complementarity.

Productivity of all country $i$ producers in $(\omega, j)$ is given by the product of a countrysector-specific term, $A_{i}(j)$, shared by all sector $j$ producers in country $i$, and a countryintermediate-good-specific productivity, $z_{i}(\omega, j)$, shared by all $(\omega, j)$ intermediate good pro- 
ducers in country $i$. The country-intermediate-good-specific productivity is equal to $z_{i}(\omega, j)=$ $u^{-\theta_{j}}$, where $u$ is an i.i.d random variable that is exponentially distributed with mean and variance 1 . A higher value of $\theta_{j}$ increases the dispersion of productivities across producers within sector $j$.

The production function (5) extends that in KORV to include ( $i$ ) intermediate inputs; ( $i i)$ differences in productivities across sectors, as in a standard Ricardian model, so that countries can have sectoral comparative advantages; and (iii) exponentially distributed countryintermediate-good-specific productivities within a sector, as in EK, so that our multi-country framework remains tractable.

International trade: Delivering a unit of intermediate good $(\omega, j)$ from country $i$ to country $n$ requires producing $\tau_{i n}(j) \geq 1$ units of that good in country $i$, where $\tau_{i i}(j)=1$. We assume that services are not tradable, so that $\tau_{i n}(S)$ is infinite for all $i \neq n$.

Equilibrium: Producers hire unskilled and skilled labor at wages $w_{i}$ and $s_{i}$, respectively, and rent structures and capital equipment at rental rates $v_{i}$ and $r_{i}$, respectively. The skill premium in country $i$ is defined as $s_{i} / w_{i}$. To construct prices, it is useful to define the unit cost of producers of intermediate good $(\omega, j)$ producing in country $i$ and selling in country $n$, denoted by $c_{i n}(\omega, j)$ :

$$
c_{i n}(\omega, j)=\frac{c_{i} \tau_{i n}(j)}{A_{i}(j) z_{i}(\omega, j)} .
$$

Here, $c_{i}$ is the unit cost of production for the domestic market of a producer of any intermediate $(\omega, j)$ in country $i$ with productivity $A_{i}(j) z_{i}(\omega, j)=1$, and is given by:

$$
\begin{aligned}
c_{i}= & \kappa_{i}\left[P_{i}(S)^{\varepsilon_{i}} P_{i}(M)^{1-\varepsilon_{i}}\right]^{1-\zeta_{i}} v_{i}^{\alpha_{i} \zeta_{i}} \times \\
& \left\{\mu_{i} w_{i}^{1-\sigma}+\left(1-\mu_{i}\right)\left[\lambda_{i} r_{i}^{1-\rho}+\left(1-\lambda_{i}\right) s_{i}^{1-\rho}\right]^{\frac{1-\sigma}{1-\rho}}\right\}^{\frac{\left(1-\alpha_{i}\right) \zeta_{i}}{1-\sigma}}
\end{aligned}
$$

where $\kappa_{i}$ is a constant, and $P_{i}(j)$ is the aggregate price of output in sector $j .8$

The price of intermediate $\operatorname{good}(\omega, j)$ in country $n$ is:

$$
p_{n}(\omega, j)=\min _{i}\left\{c_{i n}(\omega, j)\right\}
$$

where we have used the fact that good $(\omega, j)$ is perfectly substitutable across all potential source countries that can supply the good to country $n$. The aggregate price of sector $j$

\footnotetext{
${ }^{8}$ The constant is given by $\kappa_{i}=\left[\left(1-\zeta_{i}\right) \varepsilon_{i}^{\varepsilon_{i}}\left(1-\varepsilon_{i}\right)^{1-\varepsilon_{i}}\right]^{\zeta_{i}-1}\left[\zeta_{i} \alpha_{i}^{\alpha_{i}}\left(1-\alpha_{i}\right)^{1-\alpha_{i}}\right]^{-\zeta_{i}}$
} 
output in country $n$ is given by

$$
P_{n}(j)=\left[\int_{0}^{1} p_{n}(\omega, j)^{1-\eta_{i}(j)} d \omega\right]^{1 /\left[1-\eta_{i}(j)\right]} .
$$

The share of country $n$ 's expenditure in sector $j$ that is allocated to goods from country $i, \pi_{i n}(j)$, is given by

$$
\pi_{i n}(j)=\int_{0}^{1} p_{n}(\omega, j)_{i n}^{1-\eta_{i}(j)} \mathbb{I}_{i n}(\omega, j) d \omega / P_{n}(j)^{1-\eta_{i}(j)} .
$$

where $\mathbb{I}_{i n}(\omega, j)$ is an indicator variable that equals one if country $n$ purchases intermediate good $(\omega, j)$ from country $i$, and equals zero otherwise. The domestic expenditure share is given by $\pi_{i i}(j)$. Using the assumption of exponentially distributed productivities, one can show (see e.g. EK 2002) that in equilibrium

$$
\pi_{i n}(j)=\left[\tau_{i n}(j) \frac{c_{i}}{A_{i}(j)}\right]^{-1 / \theta_{j}} / \sum_{k=1}^{I}\left[\tau_{k n}(j) \frac{c_{k}}{A_{k}(j)}\right]^{-1 / \theta_{j}}
$$

In the following sections, we use Equation (6) to solve analytically for the change in the skill premium between any two steady states.

A competitive equilibrium is a set of prices and quantities such that all markets clear. Each producer must satisfy worldwide demand for its output. Sectoral output must satisfy the resource constraints (2), (3), and (4). The demand for unskilled and skilled labor across producers must equal the endowments $L_{i}$ and $H_{i}$, respectively. The demand for intermediate inputs of services and manufacturing must equal $X_{i}(S)$ and $X_{i}(M)$, respectively. The demand for structures and capital equipment across producers must equal their supplies $K_{i}(S)$ and $K_{i}(E)$. The supplies of each type of capital must be consistent with the household's optimal investment decisions. The household's budget constraints must be satisfied. A steady-state equilibrium is an equilibrium in which all variables remain constant over time. We characterize the steady-state equilibrium in Appendix A.

\section{Analytic Results}

In this section, we examine the central forces that shape changes in the skill premium in our model. 


\subsection{The Skill Premium}

Cost minimization implies that producers set the ratio of the marginal product of skilled labor to unskilled labor equal to the skill premium. Equation (5) and the fact that producers in all sectors use the same factor intensity imply

$$
\frac{s_{i}}{w_{i}}=\left(\frac{1-\mu_{i}}{\mu_{i}}\right)^{\frac{1}{\sigma}}\left(1-\lambda_{i}\right)^{\frac{1}{\rho}}\left(\frac{L_{i}}{H_{i}}\right)^{\frac{1}{\sigma}}\left[\lambda_{i}^{\frac{1}{\rho}}\left(\frac{K_{i}(E)}{H_{i}}\right)^{\frac{\rho-1}{\rho}}+\left(1-\lambda_{i}\right)^{\frac{1}{\rho}}\right]^{\frac{\sigma-\rho}{(\rho-1) \sigma}} .
$$

From equation (7), changes in country $i$ 's skill premium are fully determined by changes in country $i$ 's endowments of skilled and unskilled labor, and changes in its stock of capital equipment. An increase in unskilled labor relative to skilled labor increases the skill premium with an elasticity of $1 / \sigma$. An increase in capital equipment relative to skilled labor increases the skill premium if and only if $\sigma>\rho$ (that is, if skilled labor is more complementary with capital equipment than is unskilled labor). This second component captures the capital-skill complementarity effect on the skill premium.

Of course, the stock of capital equipment, $K_{i}(E)$, is endogenous, and changes in $K_{i}(E)$ potentially depend on changes in bilateral trade costs (between each pair of countries and in each sector), changes in each country-sector-specific productivity, and changes in labor endowments in each country. We can show, however, that there is a small set of sufficient statistics that fully determine the equilibrium change in the stock of capital equipment and the skill premium across steady-states. Appendix A presents a set of five equations from which the steady-state change in the stock of capital equipment and the skill premium can be calculated for any country $i$.

For given values of the elasticities of substitution $(\sigma$ and $\rho)$, the dispersion of productivities $\theta_{j}$, and factor shares in the initial equilibrium, the change in country $i$ 's skill premium depends only on: $(i)$ changes in domestic expenditure shares, $\pi_{i i}(j)$ for all $j$; $(i i)$ changes in domestic technologies, $A_{i}(j)$ for all $j$; and (iii) changes in domestic endowments, $H_{i}$ and $L_{i}$. Importantly, conditional on $(i)-(i i i)$, changes in trade costs, changes in other countries' technologies and endowments, and changes in all other trade shares do not affect the change in country $i$ 's skill premium. That is, international trade, foreign technologies, and foreign endowments only affect country $i$ 's skill premium through $\pi_{i i}(j)$. Moreover, for a given change in domestic expenditure shares $\pi_{i i}(j)$, we do not need to compute the multi-country general equilibrium model to calculate the change in country $i$ 's skill premium.

Incorporating differences in factor intensities across sectors: In Appendix $\mathrm{C}$ we briefly discuss an extension of our basic environment that relaxes our assumption that factor intensities are common across sectors. In particular, we allow for the parameters of the 
production function $\{\varepsilon, \zeta, \alpha, \mu, \lambda, \rho, \sigma\}$ to all vary across sectors. We show that changes in a country's skill premium are not only determined by changes in domestic productivities, domestic labor endowments, and domestic expenditure shares - as in our baseline model - but also by changes in the factor-content of trade (i.e., the amount of each factor embodied in a country's net exports). ${ }^{9}$ This extended model thus embeds the standard Stolper-Samuelson effect, through which international trade raises the relative return of the factor used intensively in the comparative advantage sector. We show, however, that conditional on observing changes in domestic productivities, domestic labor endowments, domestic expenditure shares, and the factor-content of trade in country $i$, one can still calculate changes in country $i$ 's skill premium without actually computing the multi-country general equilibrium model.

\subsection{First-Order Approximation}

To better understand the role of changes in $(i)$ domestic expenditure shares, $(i i)$ domestic technologies, and (iii) domestic endowments in shaping changes in the skill premium, we log-linearize the steady-state equilibrium equations. In Appendix B we show that the change in the skill premium is, to a first-order approximation, given by

$$
\widehat{s}_{i}-\widehat{w}_{i}=-\frac{\xi_{i}^{H}+\xi_{i}^{L}}{\rho \xi_{i}^{L}+\sigma \xi_{i}^{H}}\left(\widehat{H}_{i}-\widehat{L}_{i}\right)+\Theta_{i} \sum_{j} \varkappa_{i}(j)\left[\widehat{A}_{i}(j)-\theta_{j} \widehat{\pi}_{i i}(j)\right],
$$

where variables with hats denote $\log$ differences, $\xi_{i}^{H}$ denotes the steady-state ratio of skilled labor payments to capital equipment payments, and $\xi_{i}^{L}$ denotes the steady-state ratio of unskilled labor payments to the sum of all labor payments and payments to capital equipment,

$$
\xi_{i}^{H}=\frac{s_{i} H_{i}}{r_{i} K_{i}(E)} \quad \text { and } \quad \xi_{i}^{L}=\frac{w_{i} L_{i}}{w_{i} L_{i}+s_{i} H_{i}+r_{i} K_{i}(E)} .
$$

The elasticity of the skill premium with respect to a change in $\left[\widehat{A}_{i}(j)-\theta_{j} \widehat{\pi}_{i i}(j)\right]$ is given by $\Theta_{i} \varkappa_{i}(j)$, where

$$
\Theta_{i}=\frac{\sigma-\rho}{\rho \xi_{i}^{L}+\sigma \xi_{i}^{H}}
$$

\footnotetext{
${ }^{9}$ See Burstein and Vogel (2011) for a discussion of the factor content of trade in a general class of trade models.
} 
is common across sectors, and where

$$
\varkappa_{i}(j)= \begin{cases}\frac{\left(1-\zeta_{i}\right) \varepsilon_{i}+\zeta_{i} \alpha_{i}}{\zeta_{i}\left(1-\alpha_{i}\right)} & \text { if } j=S \\ \frac{\left(1-\zeta_{i}\right)\left(1-\varepsilon_{i}\right)}{\zeta_{i}\left(1-\alpha_{i}\right)} & \text { if } j=M \\ 1 & \text { if } j=E\end{cases}
$$

is a function of production function parameters and varies across sectors.

Decomposing changes in the skill premium: Equation (8) decomposes the change in the skill premium into four components. The first component depends on the growth of unskilled labor relative to skilled labor and captures the relative supply effect already present in equation (7). All else equal, an increase in the relative supply of skills reduces the skill premium with an elasticity of $\left(\xi_{i}^{H}+\xi_{i}^{L}\right) /\left(\rho \xi_{i}^{L}+\sigma \xi_{i}^{H}\right)$.

The second, third, and fourth components $(j=S, M$, and $E)$ are all contained in the second term of equation (8). Each component depends on changes in sector $j$ 's productivity and domestic expenditure share and captures the capital-skill complementarity effect. All else equal, an increase in $\left[\widehat{A}_{i}(j)-\theta_{j} \widehat{\pi}_{i i}(j)\right]$ raises the skill premium with an elasticity of $\Theta_{i} \varkappa_{i}(j)$. If $\sigma>\rho$, so that $\Theta_{i}>0$, then an increase in the supply of capital equipment relative to skilled labor increases the skill premium, as shown in equation (7). Here, we describe why an increase in $\widehat{A}_{i}(j)-\theta_{j} \widehat{\pi}_{i i}(j)$ for all $j$ tends to raise $K_{i}(E)$, and hence the skill premium.

Intuitively, country $i$ 's stock of equipment rises either through increased domestic production or increased imports of equipment. All else equal, country $i$ produces more equipment as $A_{i}(E)$ rises, and imports more equipment as $\pi_{i i}(E)$ falls.

Country $i$ 's supply of equipment also rises with an increase in $\widehat{A}_{i}(j)-\theta_{j} \widehat{\pi}_{i i}(j)$, for $j=S, M$. Intuitively, in equilibrium $X_{i}(S)$ and $X_{i}(M)$ rise with $\widehat{A}_{i}(j)-\theta_{j} \widehat{\pi}_{i i}(j)$ for $j=S$ and $j=M$, respectively, for the same reason that $K_{i}(E)$ rises with $\widehat{A}_{i}(E)-\theta_{j} \widehat{\pi}_{i i}(E)$. Because $X_{i}(S)$ and $X_{i}(M)$ are used as inputs in the production of equipment, the stock of equipment rises as well. Moreover, the stock of capital equipment increases with $\widehat{A}_{i}(S)$ even if services are not used as intermediate inputs, i.e., even if $\varepsilon_{i}=0$, because structures are used directly as an input in production, if $\zeta_{i}>0$.

The elasticity of the skill premium: Equation (8) provides the elasticity of a country's skill premium with respect to each of its sectoral productivities, $\Theta_{i} \varkappa_{i}(j)$, and each of its domestic sectoral expenditure shares, $-\Theta_{i} \varkappa_{i}(j) \theta_{j}$. These elasticities have clear economic interpretations that highlight the roles played by different model parameters and they allow us to conduct sensitivity analyses analytically.

A higher value of within-sector technological dispersion, $\theta_{j}$, tends to magnify the impact 
of changes in trade shares on the skill premium. This follows from the fact that for a given domestic expenditure share in the equipment sector (as an example), the increase in the stock of equipment generated by trade is greater for higher values of $\theta_{j}$. Intuitively, when productivity dispersion rises, the cost differential between imported varieties and the domestic varieties they replace becomes greater, so that the same reduction in the domestic expenditure share leads to a greater increase in the stock of equipment.

Similarly, a higher value of the elasticity $\Theta_{i} \varkappa_{i}(j)$ tends to magnify the impact of changes in $\widehat{A}_{i}(j)-\theta_{j} \widehat{\pi}_{i i}(j)$ on the skill premium. A higher value of $\Theta_{i}$ corresponds to stronger capital-skill complementarity. Inspecting equation (10), it is apparent that sectors that are more important in the production of capital equipment have a higher value of $\varkappa_{i}(j)$, and hence have a higher elasticity of the skill premium with respect to $\widehat{A}_{i}(j)-\theta_{j} \widehat{\pi}_{i i}(j)$. Perhaps surprisingly, the sum of the elasticities of manufacturing and services can potentially be larger than that of equipment. Intuitively, this is more likely to occur when manufacturing and services play a larger role in the production of equipment, which occurs if the share of intermediate inputs in production is high (i.e., if $\zeta_{i}$ is low) and if the share of services in value added is high (i.e., if $\alpha_{i}$ is high). Note that the equipment stock and the skill premium rise if there is growth in technology and trade in manufacturing, equipment, or servicesregardless of the sector in which growth is greatest - whereas the price of equipment relative to consumption falls if technological and trade growth are relatively larger in the equipment sector:

$$
\widehat{P}_{i}(E)-\widehat{P}_{i}(M)=\widehat{A}_{i}(M)-\widehat{A}_{i}(E)+\theta_{E} \widehat{\pi}_{i i}(E)-\theta_{M} \widehat{\pi}_{i i}(M) .
$$

Hence, an increase in the stock of equipment is not necessarily accompanied by a decline in the relative price of equipment to consumption goods, and vice versa.

Summary: We summarize the previous results in the following Proposition.

Proposition 1 In any equilibrium, the skill premium in country $i$ is given by equation (7), and the change in the skill premium in country $i$ across two steady-states is, to a first-order approximation, given by equation (8).

\section{Quantitative Results}

In this section we use our model to quantify the impact of changing trade flows on the skill premium in multiple countries. We conduct two counterfactuals. In the first, we determine how much each country's skill premium would change if it were moved to autarky because of increases in trade costs. In the second, we determine the impact of changes in observed trade flows on each country's skill premium. 
Through these counterfactuals, we are interested in addressing the extent to which countries may import skill-biased technology and a rise in the skill premium. We are not directly concerned with whether a change in trade patterns is driven by changing technologies or by changing trade costs. Hence, we take as given changing trade flows in the second counterfactual, without determining their underlying causes.

These counterfactuals exploit the simple structure of our model, which allows us to conduct these exercises country-by-country because the impact of changes in any foreign technology, foreign factor endowment, or trade cost is transmitted only through changes in domestic expenditure shares, which we take as given. Hence, we are able to conduct each counterfactual without computing the full multi-country general equilibrium.

While we solve for exact changes in the skill premium, using the system of equations provided in Appendix A, the intuition for our results all derive from equation (8), which provides a first-order approximation to changes in the skill premium. We replicate these two counterfactuals using only equation (8), and show that this approximation is quite accurate.

To conduct our counterfactuals we need information on domestic expenditure shares, $\pi_{i i}(j)$, and we need to parameterize our model. In what follows, we first describe how we construct domestic expenditure shares and how we parameterize the model. Further details are provided in Appendix D. Finally, we present the quantitative results.

\subsection{Domestic Expenditure Shares}

To construct domestic expenditure shares, $\pi_{i i}(E)$ and $\pi_{i i}(M)$, we use trade and production data and compute expenditures as the difference between gross output and net exports. Trade data comes from Feenstra et. al. (2005), which contains data by commodity, disaggregated at the 4-digit Standard International Trade Classification (SITC) level, for the 1962-2000 period. For gross output data, we use the UNIDO Industrial Statistics Database, which covers the 1963-2007 period and is arranged at the 2-digit level of the third revision of the International Standard Industrial Classification (ISIC Rev. 3).

We follow Eaton and Kortum (2001), who group manufactured commodities into equipment goods and other manufacturing goods using input-output tables and capital flows tables of domestic transactions (OECD, 1996) for the three major capital goods producers (Germany, Japan, and the US). For trade data, we match 4 digit SITC codes to a set of industry codes used by the Bureau of Economic Analysis (BEA). Following Eaton and Kortum, we define equipment trade as the sum of BEA industry codes 20-27 and 33.

For gross output data, Eaton and Kortum identify three ISIC Rev. 2 industries as

equipment producers: non-electrical equipment, electrical equipment, and instruments. We 
define equipment producers as the ISIC Rev. 3 industries that most closely correspond to the ISIC Rev. 2 industries identified by Eaton and Kortum. ${ }^{10}$ In particular, we define equipment commodities to be the sum of ISIC Rev. 3 codes 29-33.

After combining these datasets, we are left with 53 countries for which both data on trade and output is available until at least 1995. For each country in our sample, our counterfactuals are based on the first and last year with available data. Importantly, we do not require a balanced panel because we do not need data on changes in any country $n \neq i$ when solving for the change in the skill premium in country $i$ in our counterfactuals.

We report the resulting domestic expenditure shares in Table 2. Two features are striking from the table. First, as noticed by Eaton and Kortum (2001), most countries import a significant fraction of their capital equipment. For the median country in our sample, the import share of equipment in the year 2000 is roughly $1-0.25=0.75$, more than twice as large as the import share for other manufactured goods. Note that these import shares are large for countries at different stages of the development process, including developed countries such as Canada and the UK. Second, most countries experienced sizable increases in their import shares over our sample period, especially in the equipment sector. A notable exception are the poorest countries in the sample, which were already importing almost all of their equipment at the beginning of the sample. The median values across countries for the changes in the domestic expenditure shares in equipment and manufacturing, $\widehat{\pi}_{i i}(E)$ and $\widehat{\pi}_{i i}(M)$, are -0.3 and -0.15 , respectively.

The fact that $\pi_{i i}(E)$ tends to be lower in developing countries might suggest that the relative price level of equipment is higher in these countries; see e.g. Eaton and Kortum (2001) and Hsieh and Klenow (2007). In our model, this relative price depends on a combination of trade costs and productivities in each country. Since our parameterization does not separately identify trade costs and productivities in each country, our paper is silent on our model's implications for these relative prices. $^{11}$

\subsection{Parameterization}

By inspecting the set of equations that determines the change in the skill premium in our counterfactuals (described in Appendix A) and in the log-linearized equation (8), the parameters that we must choose are those that determine the elasticities of substitution between capital equipment, unskilled labor, and skilled labor, $\sigma$ and $\rho$; the within-sector dispersion of

\footnotetext{
${ }^{10}$ UNIDO discontinued its Industrial Statistics Database using ISIC Rev. 2.

${ }^{11}$ Waugh (2010) shows that quantitative Ricardian models are consistent with observed differences across countries in the level of tradeable goods prices if one allows for asymmetric trade costs (e.g. $\left.\tau_{i n}(j) \neq \tau_{n i}(j)\right)$, as we do in this paper.
} 
productivity, $\theta_{j}$; the share of value added in production, $\zeta_{i}$; the share of services in intermediate inputs, $\varepsilon_{i}$; and the share of structures in value added, $\alpha_{i}$. In addition, we must choose initial values for relative factor shares $\xi_{i}^{L}$ and $\xi_{i}^{H}$ (which, given other parameters values, determine $\lambda_{i}$ and $\mu_{i}$ ). These parameters determine jointly the elasticity of the skill premium with respect to trade shares, given by $\Theta_{i} \varkappa_{i}(j) \theta_{j}$ in equation (8). We assume that all of the above parameters are common across countries and sectors. We now provide an overview of our baseline procedure, the results of which are summarized in Table 1.

Baseline parameterization: We set $\theta_{j}=0.2$ for all $j$. This parameter, which controls the within-sector dispersion of productivity, plays a central role in quantitative trade models because it determines the elasticity of imports with respect to trade costs in equilibrium, as can be seen in equation (6). Our choice of $\theta=0.2$ implies an elasticity of 5 , which is within the range of elasticities estimated in the trade literature; see, e.g., Eaton and Kortum (2002), Bernard, Eaton, Jensen, and Kortum (2003), Anderson and Van Wincoop (2004), Donaldson (2010), Simonovska and Waugh (2011), and Costinot, Donaldson, and Komunjer (Forthcoming).

We pick $\zeta, \varepsilon, \alpha, \xi^{L}, \xi^{H}, \sigma$ and $\rho$ to match certain features of US data between 1963 and 2000. We calibrate the share of value added in gross output, $\zeta$, and the share of services in intermediate inputs, $\varepsilon$, using US Input-Output tables for the year 2000 from the OECD Input-Output database. ${ }^{12}$ We calibrate $\alpha, \xi^{L}$, and $\xi^{H}$ to match observed factor shares, which are obtained as follows. We calculate the labor share in value added from NIPA as the ratio of compensation for employees to value added less taxes, in the corporate and non-corporate business sector. We disaggregate labor payments into skilled and unskilled labor using data on quantities and prices of skilled and unskilled labor from Polgreen and Silos (2008), who use detailed CPS data. We disaggregate capital payments into structures and equipment using data on the value of capital stocks and, since rental rates are not directly observable, using the steady-state Euler equations of our model for the accumulation of each type of capital, where a time period represents a year (further details are provided in Appendix D). We set $\alpha, \xi^{L}$, and $\xi^{H}$ to equal the respective relative factor shares on average between 1963 and 2000. ${ }^{13}$ This procedure implies $\alpha=0.1, \xi^{L}=0.53$, and $\xi^{H}=1.04 .^{14}$

\footnotetext{
${ }^{12}$ These shares were $\zeta=0.54$, and $\varepsilon=0.6$ in 2000 .

${ }^{13}$ Factor shares $\xi^{H}$ and $\xi^{L}$ in the U.S. changed considerably in our time period (e.g. the payments to capital equipment rise over time relative to the payments to skilled labor). If we calibrated the model to the initial share levels in 1963, then the elasticity of the skill premium to trade flows would be significantly larger than the one in our baseline parameterization.

${ }^{14}$ We assume that factor shares are identical across countries because of data limitations only. If, contrary to our assumption, developing countries have lower equipment shares (or lower skill shares), then $\Theta_{i}$ would be lower (higher) in developing countries. Our assumption that the labor share is not systematically correlated with a country's level of development is consistent with evidence in Gollin (2002). In our model the labor share changes in response to the changes in trade shares we feed in from the data, but quantitatively these
} 
The two final, and key parameters whose values we need to pick are $\sigma$ and $\rho$. We pursue several strategies to parameterize these. In our baseline parameterization, we calibrate $\sigma$ and $\rho$ so that our model reproduces the observed cumulative changes in factor shares and the skill premium in the US between 1963 and 2000, given the observed changes in the supplies of capital equipment and of skilled and unskilled labor. In particular, we use the two following equations

$$
\begin{gathered}
\rho^{-1}=1+\frac{\widehat{\xi^{H}}}{\widehat{K(E) / H}} \\
\sigma=\frac{(\rho-1) \widehat{(H / L)}+\rho\left(\widehat{1+1 / \xi^{H}}\right)}{(1-\rho) \widehat{(s / w)}+\left(\widehat{1+1 / \xi^{H}}\right)},
\end{gathered}
$$

where variables with hats denote log differences between 1963 and 2000. Equation (11) is obtained by log-differentiating the producers' first-order condition for capital equipment relative to skilled labor. Equation (12) is obtained by log-differentiating equation (7). In solving for $\rho$ and $\sigma$, we use data on changes in the skill premium and on the stocks of (quality adjusted) capital equipment, skilled labor and unskilled labor from Polgreen and Silos (2008). This procedure implies $\rho=0.63$ and $\sigma=1.56 .^{15}$

With these parameters, the elasticity of the skill premium with respect to $\widehat{A}_{i}(j)-\theta \widehat{\pi}_{i i}(j)$ in all countries is $\Theta=0.48$ for equipment goods and $\Theta \varkappa_{i}(M)=0.48 * 0.37=0.18$ for manufacturing goods, from equation (8). ${ }^{16}$ Together with our value of $\theta$, this implies an elasticity of the skill premium with respect to domestic expenditure shares $\theta \Theta \varkappa(j)$ in equipment and manufacturing of 0.10 and 0.04 , respectively. Conducting sensitivity analyses of these elasticities with respect to changes in parameter values is straightforward using equation (8). Alternative parameterizations of $\sigma$ and $\rho$ : We pursue several alternative strategies to parameterize $\rho$ and $\sigma$. First, rather than calibrating $\rho$ and $\sigma$ so that our model reproduces the observed cumulative changes in factor shares and the skill premium in the US between 1963 and 2000, we estimate $\rho$ and $\sigma$ via non-linear least squares, using equations (11) and (12) and annual changes in factor shares and the skill premium in the US over the same time period. We obtain $\rho=0.66$ and $\sigma=1.47,{ }^{17}$ from which we obtain $\Theta=0.43$.

changes are very small.

${ }^{15}$ In a multi-factor production function there are several alternative definitions of the elasticity of substitution between two factors. In our baseline parameterization, the Allen partial elasticity of substitution between skilled and unskilled labor is 1.56 while the direct partial elasticity of substitution between these two factors is 1.04, using the definitions in Sato (1967).

${ }^{16}$ Using measures of changes in labor supplies and the skill premium from Acemoglu and Autor (2010) we obtain $\Theta=0.49$. If we parameterize our model using data from 1963 to 1992 as in KORV (as opposed to 1963-2000), we obtain $\Theta=0.50$. Using the values of the elasticities $\sigma$ and $\rho$ estimated in KORV we obtain $\Theta=0.44$.

${ }^{17}$ The standard errors on our estimates of $\rho$ and $\sigma$ are 0.016 and 0.076 , respectively. 
Second, we calibrate our model allowing for skill-biased technical change, an additional mechanism to capital-skill complementarity that raises the skill premium over time. In particular, we allow for exogenous trend growth in the productivity of the composite of skilled labor and capital equipment relative to unskilled labor, extending the approach of Katz and Murphy (1992). To do so we replace the term $\left(1-\mu_{i}\right)^{1 / \sigma}$ in equation (5) with $A(t)\left(1-\mu_{i}\right)^{1 / \sigma}$, where $A(t)=\exp (\varphi t)$ and $\varphi$ denotes the annual trend. ${ }^{18}$ We adjust equation (12) accordingly. Feeding in a value of $\varphi=0.01,0.02$, or 0.03 into our calibration procedure lowers $\Theta$ from 0.48 to $0.37,0.27$, or 0.18 , respectively. The annual trend would have to be as large as $\varphi=0.052$ in order for capital-skill complementarity to be absent, i.e. $\rho \geq \sigma$.

Finally, to assess the degree of capital-skill complementarity in a developing country that is a net importer of capital equipment, we re-parameterize $\rho$ and $\sigma$ using data from Chile. We use data on changes in the skill premium and on the stocks of capital equipment (not adjusted for quality), skilled labor and unskilled labor for the time period 1974-2000 from Gallego (Forthcoming). We adjust the stock of capital equipment using the same adjustment factor as in the US, obtained from Polgreen and Silos (2008). We calculate the labor share in value added as the ratio of the sum of compensation for employees and the surplus of enterprises owned by households to the sum of compensation for employees and all operating surplus. ${ }^{19}$ Due to a lack of data on prices and on depreciation rates of capital equipment and structures, we assume that the share of structures in value added is the same in Chile as in the US, $\alpha=0.1$. Since the Chilean data series is much more volatile than that in the US, our baseline calibration is more sensitive to the two years chosen. Nevertheless, we always find that there is strong capital-skill complementarity. When we estimate $\rho$ and $\sigma$ using annual changes in factor shares and the skill premium in Chile over the years 1974-2000 we obtain $\rho=0.53$ and $\sigma=1.54 .^{20}$ Together with the factor shares, these elasticities imply $\Theta=0.69$. The elasticities $\rho$ and $\sigma$ are very close to those that we had calibrated and estimated using US data, while $\Theta$ is larger due to differences in our measures of factor shares between Chile and the US.

\footnotetext{
${ }^{18}$ As an example, $\varphi=0.01$ implies that the skill premium rises by $1 \%$ per year, all else equal.

${ }^{19}$ We only have data on surplus of enterprises owned by households (Mixed Income) between 1996-2002. We assume that in the years 1974-2000, the ratio of Mixed Income to Operating Surplus equals 0.196, which is the average for the 1996-2002 period. The source of this data is the National Accounts Official Country Data from the United Nations Statistics Division.

${ }^{20}$ The standard errors on our estimates of $\rho$ and $\sigma$ are 0.037 and 0.202 , respectively.
} 


\subsection{Results}

We now quantify the impact of international trade, through capital-skill complementarity, on the skill premium. We perform two counterfactual exercises using our baseline parameterization.

Counterfactual 1-Autarky: In our first counterfactual, we ask: By how much would the skill premium decrease if countries move from the trade levels observed in 2000 to autarky in both equipment and manufacturing (by increasing trade costs to infinity)? The numbers from our counterfactuals are reported in Table 3. The results of our first counterfactual exercise are summarized in Figure 1, which plots the logarithmic change in the domestic expenditure share in the equipment sector, moving from the year 2000 to autarky (x-axis), and the logarithmic change in the skill premium (y-axis). The circles in Figure 1 show the counterfactual decrease in the skill premium for each country. Absent international trade in both capital equipment and manufactures, the skill premium would be roughly $5 \%$ smaller in the US and $16 \%$ smaller in the median country. The decrease is much larger for countries that are very dependent on imports of capital equipment, such as Cameroon and the Czech Republic. On the other extreme, the decline in the skill premium is only $2 \%$ for Japan.

The line in Figure 1 shows the log change in the skill premium resulting from shutting down trade in equipment goods, while keeping trade shares in the manufacturing sector constant. All circles lie below the line because imports of manufactured goods contribute to increase the stock of equipment and the skill premium. The distance between the circles and the line is large for some countries such as Bulgaria, Slovakia, and Greece, which import a substantial share of their manufacturing absorption. However, for most countries, trade in equipment is significantly more important than in manufacturing in driving the change in the skill premium, because both the 2000 import share and the elasticity of the skill premium with respect to a change in the import share are larger for equipment than for manufacturing.

To assess the accuracy of our first-order approximation of the change in the skill premium, Table 3 reports the change in the skill premium of going to autarky implied from equation (8). Across our set of countries, the median and maximum difference between the exact and approximated change in the skill premium are $1 \%$ and $9 \%$, respectively (which represent $7 \%$ and $19 \%$, respectively, of the exact change in the skill premium). Of course, the approximation error is larger for countries with lower domestic expenditures shares.

Counterfactual 2-Observed changes in trade shares: In our second counterfactual, we ask: By how much would the skill premium change if countries move from the trade levels observed in 2000, or the closest year with available information, to those observed at the 
beginning of the sample period? This counterfactual shows the impact of observed changes in trade flows on each country's skill premium during our sample period. The results are summarized in Figure 2, which displays the logarithmic change in the domestic expenditure share in the equipment sector (x-axis) and the logarithmic change in the skill premium (y-axis).

We find that international trade tends to play an important role in shaping the skill premium, but that its importance varies widely across countries in our sample depending on the magnitude of the changes in the domestic expenditure shares in equipment and other manufactured goods. While the counterfactual change in the skill premium is $-6 \%$ for the median country of our sample, and $-5 \%$ for the US, the decline in the skill premium is quite large in various developing countries such as Argentina, Chile, Colombia, Greece, and Uruguay, and in some developed countries such as Canada and the UK. ${ }^{21}$ Note that for countries in the northwest corner of Figure 2, domestic expenditure shares in the equipment sector rose during our sample period, so that moving from the domestic expenditure shares in equipment observed in 2000 to those in the base year contribute to increasing the skill premium.

Once again, trade in equipment plays a more significant role than trade in other manufactured goods in shaping the change in skill premium. This is reflected by the relatively small distance between the circles and the line in Figure 2.

Table 3 reports the approximate changes in the skill premium from equation (8). The median and maximum differences between the exact and approximated changes in the skill premium are only $0.3 \%$ and $4 \%$, respectively (which represent $4.7 \%$ and $12 \%$, respectively, of the exact change in the skill premium). Overall, equation (8) is remarkably accurate.

\section{Conclusions}

In this paper we develop a theory of international trade in which capital embodies skill-biased technology. We use the model to assess the extent to which international trade, by inducing a rise in the stock of capital, increases the demand for skilled labor and, therefore, the skill premium. We analytically provide simple sufficient statistics that determine the magnitude of the rise in the skill premium from international trade. For given parameter values, changes in

\footnotetext{
${ }^{21}$ For some countries, these number are quite large when compared to the observed increase in the skill premium over a similar time period. For example, the skill premium increased $22 \%$ in Canada between 1978-2006, 12\% in the UK between 1978-2005, $20 \%$ in Argentina between 1992-1998, and 16\% in Colombia between 1986-1998; see Krueger et. al. (2010) and Goldberg and Pavnick (2007). For the U.S., the number is not very large relative to the $25 \%$ rise in the composition-adjusted skill premium between 1963-2000; see Acemoglu and Autor (2010).
} 
domestic expenditure shares fully summarize the effects on the skill premium of all changes in trade patterns, whether generated by changes in foreign technologies, domestic technologies, or trade costs. Based on this logic, we perform a range of counterfactuals to assess the quantitative importance of international trade on the rise in the skill premium. We find that international trade can have a substantial impact on the skill premium, especially in countries that import a large fraction of their equipment.

In our quantitative analysis, we make three choices that deserve further discussion. First, we focus on steady-state equilibria, abstracting from the transition dynamics of the skill premium as countries open up to trade and gradually accumulate capital; see e.g. Stokey (1996). Second, we parameterize the degree of capital-skill complementarity to match observed changes in aggregate factor shares and the skill premium in the US and in Chile. An alternative approach would be to make use of micro-level evidence on the relationship between skill intensity and capital intensity at the producer level. This would require extending the model to allow for heterogeneity in factor intensity across producers within a country and sector. ${ }^{22}$ Third, we assume that the degree of capital-skill complementarity is common across each type of equipment capital. If, however, different types of equipment exhibit different degrees of capital-skill complementarity, then countries might choose to invest in and import different mixes of equipment depending on their relative endowment of skilled to unskilled labor; see e.g. Caselli and Wilson (2004). ${ }^{23}$

While we focus on the implications of changes in trade patterns for the skill premium, our framework can be applied to study the importance of skill-biased technical change as well. In particular, by incorporating factor-specific technical change into our production function, as we do in the sensitivity analysis in Section 4.2, we obtain an equation that extends Tinbergen's (1974, 1975) pioneering work-what Autor and Acemoglu (2010) call the canonical model - to include the effects on the skill premium not only of labor endowment and skill-biased technical changes, but also of changes in the pattern of international trade.

Finally, in this paper we model the international transfer of skill-biased technology through trade in capital goods. We abstract from other potentially important channels by which technologies diffuse across countries, such as multinational production, see, e.g., Burstein and Monge-Naranjo (2009) and Ramondo and Rodriguez-Clare (2010); migration, see, e.g., Gandal, Hanson, and Slaughter (2004); or spillovers, see, e.g., Coe and Helpman

\footnotetext{
${ }^{22}$ Burstein and Vogel (2010) provide a related model in which producer productivity is positively correlated with skill intensity. With this heterogeneity, one loses the tractable gravity structure of the model, even at the sectoral level.

${ }^{23}$ Such an extension would have to be consistent with our finding that the extent of capital-skill complementarity is similar in the US and Chile. Moreover, if imported capital exhibits a greater degree of capital-skill complementarity than domestically produced capital, then trade will raise the skill premium.
} 
(1995) and Gancia, Müller, and Zilibotti (2010). We also abstract from endogenous skillbiased technical change through innovation, see, e.g., Acemoglu (2003) and Bloom, Draca, and Van Reenen (2011). Understanding the quantitative link between globalization and inequality through these alternative channels remains an important area for future research. 


\section{References}

Acemoglu, Daron (2003), "Patterns of Skill Premia," Review of Economic Studies, Vol. 70, No. 2, pp. 199-230.

Acemoglu, Daron and David H. Autor (2010), "Skills, Tasks and Technologies: Implications for Employment and Earnings," in Orley Ashenfelter and David E. Card, eds., Handbook of Labor Economics, Vol. 4, Elsevier.

Arkolakis, Costas, Arnaud Costinot, and Andrés Rodríguez-Clare (Forthcoming), "New Trade Models, Same Old Gains?" American Economic Review.

Anderson, James E. and Eric Van Wincoop (2004), "Trade Costs," Journal of Economic Literature, Vol. 42, No. 3, pp. 691-751.

Bernard, Andrew B., Jonathan Eaton, J. Bradford Jensen, and Samuel Kortum (2003), "Plants and Productivity in International Trade," American Economic Review, Vol. 93, No. 4, pp. 1268-1290.

Bloom, Nick, Mirko Draca, and John Van Reenen (2011), "Trade Induced Technical Change: The Impact of Chinese Imports on IT and Innovation," mimeo Stanford University.

Burstein, Ariel and Alexander Monge-Naranjo (2009), "Foreign Know-How, Firm Control, and the Income of Developing Countries," Quarterly Journal of Economics, Vol. 124, No. 1, pp. 149-195.

Burstein, Ariel and Jonathan Vogel (2010), "Globalization, Technology, and the Skill Premium: A Quantitative Analysis," NBER Working Paper 16459.

Burstein, Ariel and Jonathan Vogel (2011), "Factor Prices and International Trade: A Unifying Perspective," NBER Working Paper 16904.

Bustos, Paula (2011a), "Trade Liberalization, Exports and Technology Upgrading: Evidence on the impact of MERCOSUR on Argentinian Firms," American Economic Review, Vol. 101, No. 1, pp. 304-340.

Bustos, Paula (2011b), "The Impact of Trade Liberalization on Skill Upgrading. Evidence from Argentina," Mimeo Crei.

Caselli, Francesco and Daniel J. Wilson (2004), "Importing Technology," Journal of Monetary Economics, Vol. 51, pp. 1-32. 
Coe, David T. and Elhanan Helpman (1995), "International R\&D Spillovers," European Economic Review, Vol. 39, No. 5, pp. 859-887.

Costinot, Arnaud, Dave Donaldson, and Ivana Komunjer (Forthcoming), "What Goods do Countries Trade? A Quantitative Exploration of Ricardo's Ideas," Review of Economic Studies.

Donaldson, Dave (2010), "Railroads of the Raj: Estimating the Impact of Transportation Infrastructure," mimeo MIT.

Eaton, Jonathan and Samuel Kortum (2001), "Trade in Capital Goods," European Economic Review, Vol. 45, No. 7, pp. 1195-1235.

Eaton, Jonathan and Samuel Kortum (2002), "Technology, Geography, and Trade," Econometrica, Vol. 70, No. 5, pp. 1741-1779.

Feenstra, Robert C., Robert E. Lipsey, Haiyan Deng, Alyson C. Ma, and Hengyong Mo (2005), "World Trade Flows: 1962-2000," NBER Working Paper 11040.

Gallego, Francisco (Forthcoming), "Skill Premium in Chile: Studying Skill Upgrading in the South," World Development.

Gancia, Gino, Andreas Müller, and Fabrizio Zilibotti (2010), "Structural Development Accounting," mimeo Universitat Pompeu Fabra.

Gandal, Neil, Gordon H. Hanson, and Matthew J. Slaughter (2004), "Technology, Trade, and Adjustment to Immigration in Israel," European Economic Review, Vol. 48, No. 2, pp. $403-428$.

Goldberg, Pinelopi Koujianou and Nina Pavcnik (2007), "Distributional Effects of Globalization in Developing Countries," Journal of Economic Literature, Vol. 45, No. 1, pp. $39-82$.

Gollin, Douglas (2002), "Getting Income Shares Right," Journal of Political Economy, Vol. 110, No. 2, pp. 458-474.

Griliches, Zvi (1969), "Capital-Skill Complementarity," Review of Economics and Statistics, Vol. 51, pp. 465-468.

Hsieh, Chang-Tai and Peter J. Klenow (2007), "Relative Prices and Relative Prosperity," American Economic Review, Vol. 97, No. 3, pp. 562-585. 
Jaimovich, Nir, Seth Pruitt, and Henry E. Siu (2010), "The Demand for Youth: Implications for the Hours Volatility Puzzle," mimeo Duke University.

Katz, Lawrence F. and David H. Autor (1999), "Changes in the Wage Structure and Earnings Inequality," in Orley Ashenfelter and David Card, eds., Handbook of Labor Economics, Vol. 3, Amsterdam: North-Holland and Elsevier.

Katz, Lawrence F. and Kevin M. Murphy (1992), "Changes in Relative Wages, 1963-1987: Supply and Demand Factors," The Quarterly Journal of Economics, Vol. 107, No. 1, pp. 35-78.

Koren, Miklós and Márton Csillag (2011), "Machines and Machinists: Capital-Skill Complementarity from an International Trade Perspective," mimeo Central European University.

Krueger, Dirk, Fabrizio Perri, Luigi Pistaferri, and Giovanni L. Violante (2010), "Cross Sectional Facts for Macroeconomists," Review of Economic Dynamics, Vol. 13, No. 1, pp. 1-14.

Krusell, Per, Lee E. Ohanian, José-Víctor Ríos-Rull, and Giovanni L. Violante (2000), "Capital-Skill Complementarity and Inequality: A Macroeconomic Analysis," Econometrica, Vol. 68, No. 5, pp. 1029-1053.

Parro, Fernando (2010), "Capital-Skill Complementarity and the Skill Premium in a Quantitative Model of Trade," mimeo University of Chicago.

Polgreen, Linnea and Pedro Silos (2008), "Capital-Skill Complementarity and Inequality: A Sensitivity Analysis," Review of Economic Dynamics, Vol. 11, No. 2, pp. 302-313.

Ramondo, Natalia and Andres Rodriguez-Clare (2010), "Trade, Multinational Production, and the Gains from Openness," mimeo Penn State University.

Sato, K. (1967), "A Two-Level Constant-Elasticity-of-Substitution Production Function," Review of Economic Studies, Vol. 34, No. 2, pp. 201-218.

Simonovska, Ina and Michael Waugh (2011), "The Elasticity of Trade: Estimates and Evidence," UC Davis Working Paper No. 11-2.

Stokey, Nancy L. (1996), "Free Trade, Factor Returns, and Factor Accumulation," Journal of Economic Growth, Vol. 1, No. 4, pp. 421-447. 
Tinbergen, Jan (1974), "Substitution of Graduate by Other Labor," Kyklos, Vol. 27, pp. 217-226.

Tinbergen, Jan (1975), "Income Difference: Recent Research," Amsterdam: North-Holland Publishing Company.

Verhoogen, Eric (2008), "Trade, Quality Upgrading and Wage Inequality in the Mexican Manufacturing Sector," Quarterly Journal of Economics, Vol. 123, No. 2, pp. 489-530.

Waugh, Michael E. (2010), "International Trade and Income Differences," American Economic Review, Vol. 100, No. 5, pp. 2093-2124. 
Figure 1: Move to autarky

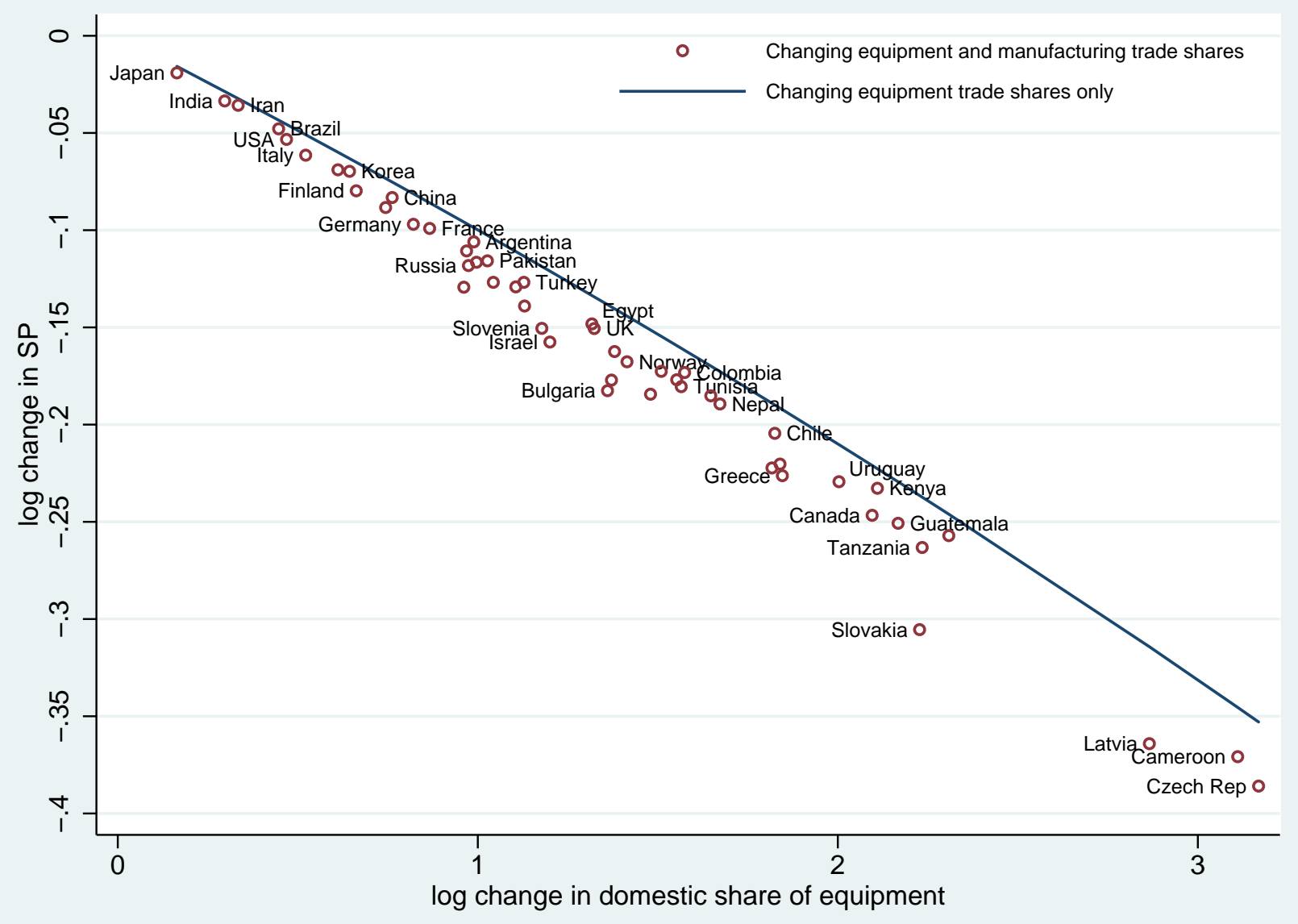

Note: Malawi (log change in SP of -0.48) is excluded from the figure. 
Figure 2: Observed changes in trade shares

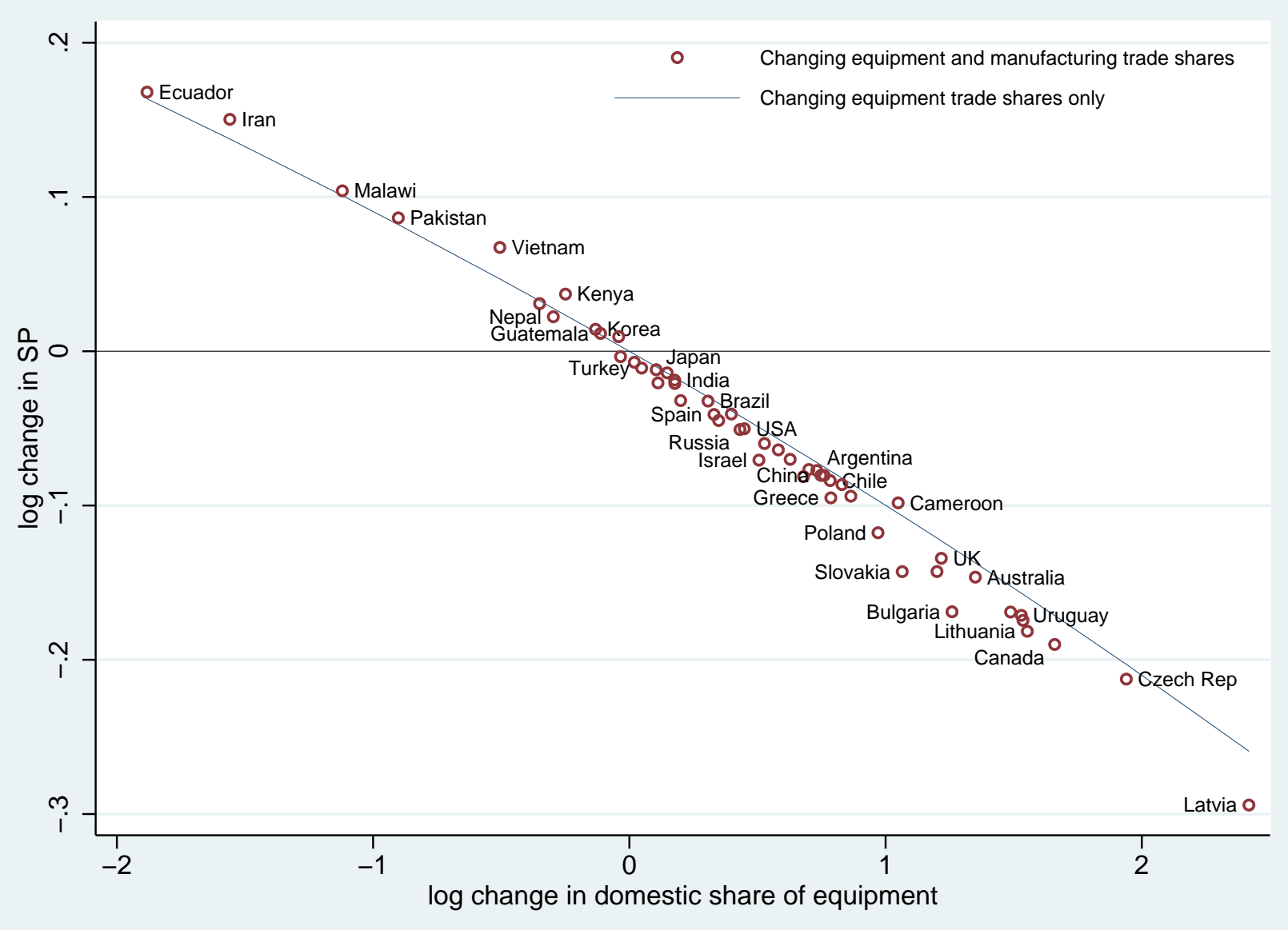


Table 1: Baseline parameter values

\begin{tabular}{cc}
\hline \hline$\sigma$ & 1.56 \\
$\rho$ & 0.63 \\
$\theta$ & 0.20 \\
$\alpha$ & 0.1 \\
$\zeta$ & 0.54 \\
$\varepsilon$ & 0.60 \\
$\xi_{i}^{H}$ & 1.04 \\
$\xi_{i}^{L}$ & 0.53
\end{tabular}




\begin{tabular}{|c|c|c|c|c|c|c|}
\hline Country & Initial year $(0)$ & Final year $(1)$ & $\pi_{i i, 0}(E)$ & $\pi_{i i, 1}(E)$ & $\pi_{i i, 0}(M)$ & $\pi_{i i, 1}(M)$ \\
\hline Argentina & 1984 & 2000 & 0.77 & 0.37 & 0.95 & 0.83 \\
\hline Australia & 1963 & 2000 & 0.74 & 0.19 & 0.87 & 0.70 \\
\hline Austria & 1963 & 2000 & 0.54 & 0.16 & 0.79 & 0.47 \\
\hline Bangladesh & 1972 & 1998 & 0.43 & 0.37 & 0.65 & 0.65 \\
\hline Brazil & 1990 & 2000 & 0.87 & 0.64 & 0.95 & 0.89 \\
\hline Bulgaria & 1980 & 2000 & 0.90 & 0.26 & 0.95 & 0.35 \\
\hline Cameroon & 1970 & 2000 & 0.13 & 0.04 & 0.50 & 0.60 \\
\hline Canada & 1963 & 2000 & 0.65 & 0.12 & 0.87 & 0.56 \\
\hline Chile & 1963 & 2000 & 0.35 & 0.16 & 0.84 & 0.71 \\
\hline China & 1977 & 2000 & 0.99 & 0.47 & 0.97 & 0.81 \\
\hline Colombia & 1963 & 2000 & 0.44 & 0.21 & 0.88 & 0.76 \\
\hline Czech Rep & 1995 & 2000 & 0.29 & 0.04 & 0.64 & 0.51 \\
\hline Denmark & 1963 & 2000 & 0.54 & 0.23 & 0.56 & 0.46 \\
\hline Ecuador & 1963 & 2000 & 0.02 & 0.10 & 0.68 & 0.78 \\
\hline Egypt & 1964 & 1998 & 0.27 & 0.27 & 0.81 & 0.70 \\
\hline Finland & 1963 & 2000 & 0.50 & 0.52 & 0.83 & 0.68 \\
\hline France & 1963 & 2000 & 0.79 & 0.42 & 0.90 & 0.72 \\
\hline Germany & 1991 & 2000 & 0.65 & 0.44 & 0.71 & 0.67 \\
\hline Greece & 1963 & 1998 & 0.35 & 0.16 & 0.71 & 0.46 \\
\hline Guatemala & 1968 & 1998 & 0.10 & 0.11 & 0.61 & 0.62 \\
\hline India & 1963 & 1999 & 0.89 & 0.74 & 0.92 & 0.88 \\
\hline Iran & 1963 & 2000 & 0.15 & 0.72 & 0.60 & 0.91 \\
\hline Israel & 1963 & 2000 & 0.50 & 0.30 & 0.72 & 0.41 \\
\hline Italy & 1967 & 2000 & 0.71 & 0.59 & 0.84 & 0.76 \\
\hline Japan & 1963 & 2000 & 0.94 & 0.85 & 0.96 & 0.91 \\
\hline Kenya & 1963 & 2000 & 0.09 & 0.12 & 0.54 & 0.80 \\
\hline Korea & 1963 & 2000 & 0.46 & 0.53 & 0.80 & 0.84 \\
\hline
\end{tabular}




\begin{tabular}{|c|c|c|c|c|c|c|}
\hline Country & Initial year $(0)$ & Final year $(1)$ & $\pi_{i i, 0}(E)$ & $\pi_{i i, 1}(E)$ & $\pi_{i i, 0}(M)$ & $\pi_{i i, 1}(M)$ \\
\hline Kyrgyzstan & 1992 & 2000 & 0.98 & 0.21 & 0.98 & 0.66 \\
\hline Latvia & 1992 & 2000 & 0.64 & 0.06 & 0.76 & 0.36 \\
\hline Lithuania & 1992 & 2000 & 0.75 & 0.16 & 0.87 & 0.52 \\
\hline Malawi & 1965 & 2000 & 0.01 & 0.02 & 0.54 & 0.59 \\
\hline Nepal & 1986 & 1996 & 0.14 & 0.19 & 0.79 & 0.68 \\
\hline Norway & 1963 & 2000 & 0.43 & 0.24 & 0.68 & 0.57 \\
\hline Pakistan & 1963 & 2000 & 0.15 & 0.36 & 0.63 & 0.72 \\
\hline Poland & 1982 & 2000 & 0.93 & 0.35 & 0.97 & 0.57 \\
\hline Portugal & 1963 & 2000 & 0.28 & 0.25 & 0.77 & 0.59 \\
\hline Romania & 1985 & 2000 & 0.98 & 0.22 & 0.97 & 0.65 \\
\hline Russia & 1996 & 2000 & 0.58 & 0.38 & 0.75 & 0.59 \\
\hline Slovakia & 1993 & 2000 & 0.31 & 0.11 & 0.54 & 0.22 \\
\hline Slovenia & 1992 & 2000 & 0.44 & 0.31 & 0.62 & 0.46 \\
\hline Spain & 1963 & 2000 & 0.53 & 0.38 & 0.90 & 0.70 \\
\hline Sweden & 1963 & 2000 & 0.67 & 0.33 & 0.78 & 0.64 \\
\hline Switz. & 1986 & 2000 & 0.58 & 0.25 & 0.45 & 0.41 \\
\hline Macedna & 1993 & 2000 & 0.47 & 0.38 & 0.61 & 0.43 \\
\hline Tanzania & 1965 & 1999 & 0.08 & 0.11 & 0.59 & 0.56 \\
\hline Tunisia & 1963 & 2000 & 0.20 & 0.21 & 0.54 & 0.63 \\
\hline Turkey & 1963 & 2000 & 0.34 & 0.32 & 0.85 & 0.72 \\
\hline UK & 1963 & 2000 & 0.90 & 0.27 & 0.89 & 0.67 \\
\hline USA & 1963 & 2000 & 0.98 & 0.63 & 0.97 & 0.82 \\
\hline Ukraine & 1992 & 2000 & 0.94 & 0.48 & 0.99 & 0.68 \\
\hline Uruguay & 1968 & 2000 & 0.62 & 0.13 & 0.91 & 0.65 \\
\hline VietNam & 1998 & 2000 & 0.19 & 0.32 & 0.29 & 0.53 \\
\hline Zimbabwe & 1964 & 1996 & 0.92 & 0.54 & 0.99 & 0.79 \\
\hline
\end{tabular}




\begin{tabular}{|c|c|c|c|c|c|c|c|c|c|}
\hline \multicolumn{10}{|c|}{ Table 3: Counterfactuals } \\
\hline \multicolumn{3}{|c|}{ Exact solution } & \multicolumn{3}{|c|}{ Approximation } & \multicolumn{2}{|c|}{ Exact solution } & \multicolumn{2}{|c|}{ Approximation } \\
\hline & Aut. & Actual & Aut. & Actual & & Aut. & Actual & Aut. & Actual \\
\hline Argentina & -0.11 & -0.08 & -0.10 & -0.07 & Kyrgyzstan & -0.18 & -0.17 & -0.16 & -0.16 \\
\hline Australia & -0.19 & -0.15 & -0.17 & -0.14 & Latvia & -0.36 & -0.29 & -0.31 & -0.26 \\
\hline Austria & -0.22 & -0.14 & -0.20 & -0.13 & Lithuania & -0.22 & -0.18 & -0.20 & -0.17 \\
\hline Bangladesh & -0.12 & -0.01 & -0.11 & -0.01 & Malawi & -0.48 & 0.10 & -0.39 & 0.11 \\
\hline Brazil & -0.05 & -0.03 & -0.05 & -0.03 & Nepal & -0.19 & 0.02 & -0.17 & 0.02 \\
\hline Bulgaria & -0.18 & -0.17 & -0.17 & -0.16 & Norway & -0.17 & -0.06 & -0.15 & -0.06 \\
\hline Cameroon & -0.37 & -0.10 & -0.31 & -0.09 & Pakistan & -0.12 & 0.09 & -0.11 & 0.09 \\
\hline Canada & -0.25 & -0.19 & -0.22 & -0.17 & Poland & -0.13 & -0.12 & -0.12 & -0.11 \\
\hline Chile & -0.20 & -0.08 & -0.19 & -0.08 & Portugal & -0.16 & -0.02 & -0.15 & -0.02 \\
\hline China & -0.08 & -0.08 & -0.08 & -0.08 & Romania & -0.17 & -0.17 & -0.16 & -0.16 \\
\hline Colombia & -0.17 & -0.08 & -0.16 & -0.08 & Russia & -0.12 & -0.05 & -0.11 & -0.05 \\
\hline Czech Rep & -0.39 & -0.21 & -0.33 & -0.19 & Slovakia & -0.31 & -0.14 & -0.27 & -0.13 \\
\hline Denmark & -0.18 & -0.09 & -0.17 & -0.09 & Slovenia & -0.15 & -0.04 & -0.14 & -0.04 \\
\hline Ecuador & -0.26 & 0.17 & -0.23 & 0.18 & Spain & -0.11 & -0.04 & -0.10 & -0.04 \\
\hline Egypt & -0.15 & -0.01 & -0.14 & -0.01 & Sweden & -0.13 & -0.08 & -0.12 & -0.07 \\
\hline Finland & -0.08 & 0.00 & -0.08 & 0.00 & Switz. & -0.18 & -0.09 & -0.16 & -0.08 \\
\hline France & -0.10 & -0.07 & -0.09 & -0.07 & Macedna & -0.13 & -0.03 & -0.12 & -0.03 \\
\hline Germany & -0.10 & -0.04 & -0.09 & -0.04 & Tanzania & -0.26 & 0.03 & -0.23 & 0.03 \\
\hline Greece & -0.23 & -0.09 & -0.20 & -0.09 & Tunisia & -0.18 & 0.01 & -0.17 & 0.01 \\
\hline Guatemala & -0.25 & 0.01 & -0.22 & 0.01 & Turkey & -0.13 & -0.01 & -0.12 & -0.01 \\
\hline India & -0.03 & -0.02 & -0.03 & -0.02 & UK & -0.15 & -0.13 & -0.14 & -0.13 \\
\hline Iran & -0.04 & 0.15 & -0.04 & 0.16 & USA & -0.05 & -0.05 & -0.05 & -0.05 \\
\hline Israel & -0.16 & -0.07 & -0.15 & -0.07 & Ukraine & -0.09 & -0.08 & -0.08 & -0.08 \\
\hline Italy & -0.06 & -0.02 & -0.06 & -0.02 & Uruguay & -0.23 & -0.17 & -0.21 & -0.16 \\
\hline Japan & -0.02 & -0.01 & -0.02 & -0.01 & Viet Nam & -0.14 & 0.07 & -0.13 & 0.07 \\
\hline Kenya & -0.23 & 0.04 & -0.21 & 0.04 & Zimbabwe & -0.07 & -0.06 & -0.07 & -0.06 \\
\hline Korea & -0.07 & 0.01 & -0.07 & 0.01 & & & & & \\
\hline
\end{tabular}

Note: Aut. refers to counterfactual of moving from 2000 trade levels to autarky. Actual refers to counterfactual of moving from 2000 trade levels to start of sample trade levels. Exact refers to exact solution, approximation refers to loglinear approximation in equation (8). 


\section{A Solving for Changes in the Skill Premium}

In this section, we show how to solve for the change in country $i$ 's skill premium as a function of changes in domestic expenditure shares, $\pi_{i i}(j)$ 's, changes in domestic technologies, $A_{i}(j)$ 's; and changes in domestic endowments, $H_{i}$ and $L_{i}$. We proceed in three steps. First, we derive the marginal costs functions and equilibrium input demands. Then, we characterize the steady state equilibrium. Finally, using the steady state equilibrium conditions, we derive the system of equations that completely characterizes the change in country $i$ 's skill premium.

\section{A.1 Marginal Cost Functions and Intermediate Inputs Demands}

We first derive the formulas for the marginal cost functions and the intermediate input demands. To simplify notation, we write the production function of $(\omega, j)$ intermediate good producers as

$$
y_{i}(\omega, j)=A_{i}(j) z_{i}(\omega, j) b_{3, i}^{\zeta_{i}} b_{4, i}^{1-\zeta_{i}}
$$

where

$$
\begin{aligned}
& b_{4, i}=x_{S}^{\varepsilon_{i}} x_{M}^{1-\varepsilon_{i}}, \quad b_{2, i}=\left[\mu_{i}^{1 / \sigma} l^{(\sigma-1) / \sigma}+\left(1-\mu_{i}\right)^{1 / \sigma} b_{1}^{(\sigma-1) / \sigma}\right]^{\sigma /(\sigma-1)}, \\
& b_{3, i}=k_{S}^{\alpha_{i}} b_{2}^{1-\alpha_{i}}, \quad \text { and } b_{1, i}=\left[\lambda_{i}^{1 / \rho} k_{E}^{(\rho-1) / \rho}+\left(1-\lambda_{i}\right)^{1 / \rho} h^{(\rho-1) / \rho}\right]^{\rho /(\rho-1)} .
\end{aligned}
$$

The unit cost of production for the domestic market of a producer with productivity $A_{i}(j) z_{i}(\omega, j)=$ 1 , which we denote by $c_{i}$, can then be expressed as

$$
c_{i}=p_{b_{3, i}}^{\zeta_{i}} p_{b_{4, i}}^{1-\zeta_{i}} / \zeta_{i}^{\zeta_{i}}\left(1-\zeta_{i}\right)^{1-\zeta_{i}}
$$

where

$$
\begin{array}{ll}
p_{b_{4, i}}=\frac{P_{i}(S)^{\varepsilon_{i}} P_{i}(M)^{1-\varepsilon_{i}}}{\varepsilon_{i}^{\varepsilon_{i}}\left(1-\varepsilon_{i}\right)^{1-\varepsilon_{i}}}, & p_{b_{2, i}}=\left[\mu_{i} w_{i}^{1-\sigma}+\left(1-\mu_{i}\right) p_{b_{1, i}}^{1-\sigma}\right]^{1 /(1-\sigma)}, \\
p_{b_{3, i}}=\frac{v_{i}^{\alpha_{i}} p_{b_{2, i}}^{1-\alpha_{i}}}{\alpha_{i}^{\alpha_{i}}\left(1-\alpha_{i}\right)^{1-\alpha_{i}}}, & \text { and } p_{b_{1, i}}=\left[\lambda_{i} r_{i}^{1-\rho}+\left(1-\lambda_{i}\right) s_{i}^{1-\rho}\right]^{1 /(1-\rho)} .
\end{array}
$$

Here, $p_{b_{4, i}}, p_{b_{3, i}}, p_{b_{2, i}}$, and $p_{b_{1, i}}$ denote the unit costs of the input bundles $b_{4, i}, b_{3, i}, b_{2, i}$, and $b_{1, i}$ in country $i$.

Profit maximization by final good producers gives rise to the following demand for $(\omega, j)$ :

$$
q_{i}(\omega, j)=\left(\frac{p_{i}(\omega, j)}{P_{i}(j)}\right)^{-\eta_{i}(j)} Y_{i}(j) .
$$

Factors demanded in the production of intermediate good $(\omega, j)$ in country $i$ for goods sold in country $n$ are given by

$$
\begin{array}{ll}
l_{\text {in }}(\omega, j)=\mu_{i}\left[\frac{p_{b_{2, i}}}{w_{i}}\right]^{\sigma} b_{2, i n}(\omega, j), & h_{\text {in }}(\omega, j)=\left(1-\lambda_{i}\right)\left[\frac{p_{b_{1, i}}}{s_{i}}\right]^{\rho} b_{1, i n}(\omega, j), \\
k_{S, i n}(\omega, j)=\alpha_{i} \frac{p_{b_{3, i}} b_{3, i n}(\omega, j)}{v_{i}}, & k_{E, i n}(\omega, j)=\lambda_{i}\left[\frac{p_{b_{1, i}}}{r_{i}}\right]^{\rho} b_{1, i n}(\omega, j), \\
x_{S, i n}(\omega, j)=\varepsilon_{i} \frac{p_{b_{4, i}} b_{4, i n}(\omega, j)}{P_{i}(S)}, & \text { and } x_{M, i n}(\omega, j)=\left(1-\varepsilon_{i}\right) \frac{p_{b_{4, i}} b_{4, i n}(\omega, j)}{P_{i}(M)},
\end{array}
$$


where

$$
\begin{array}{ll}
b_{4, i n}(\omega, j)=\left(1-\zeta_{i}\right) \frac{p_{n}(\omega, j) q_{n}(\omega, j)}{p_{b_{4, i}}} \mathbb{I}_{i n}(\omega, j), & b_{2, i n}(\omega, j)=\left(1-\alpha_{i}\right) \frac{p_{b_{3, i}} b_{3, i n}(\omega, j)}{p_{b_{2, i}}}, \\
b_{3, i n}(\omega, j)=\zeta_{i} \frac{p_{n}(\omega, j) q_{n}(\omega, j)}{p_{b_{3, i}}} \mathbb{I}_{i n}(\omega, j), & b_{1, i n}(\omega, j)=\left(1-\mu_{i}\right)\left[\frac{p_{b_{2, i}}}{p_{b_{1, i}}}\right]^{\sigma} b_{2, i n}(\omega, j),
\end{array}
$$

and where $\mathbb{I}_{i n}(\omega, j)$ is an indicator function that takes the value of one when country $i$ supplies country $n$ with intermediate good $(\omega, j)$ and is zero otherwise.

\section{A.2 Steady State Equilibrium}

We now use the above equations to characterize steady-state equilibrium aggregate variables. In what follows, we let

$$
\Phi_{i} \equiv \sum_{n} \sum_{j} \pi_{i n}(j) P_{n}(j) Y_{n}(j)
$$

denote total revenue accruing to all country $i$ producers across all sectors. Integrating factor demands across producers, and adding across all destination countries $n$ and sectors $j$, we have equilibrium in factor markets,

$$
\begin{aligned}
v_{i} K_{i}(S) & =\zeta_{i} \alpha_{i} \Phi_{i} \\
w_{i} L_{i} & =\zeta_{i} \mu_{i}\left(1-\alpha_{i}\right)\left(p_{b_{2, i}} / w_{i}\right)^{\sigma-1} \Phi_{i} \\
r_{i} K_{i}(E) & =\zeta_{i} \lambda_{i}\left(1-\alpha_{i}\right)\left(1-\mu_{i}\right)\left(\frac{p_{b_{1, i}}}{r_{i}}\right)^{\rho-1}\left(\frac{p_{b_{2, i}}}{p_{b_{1, i}}}\right)^{\sigma-1} \Phi_{i}, \\
s_{i} H_{i} & =\zeta_{i}\left(1-\alpha_{i}\right)\left(1-\mu_{i}\right)\left(1-\lambda_{i}\right)\left(\frac{p_{b_{1, i}}}{s_{i}}\right)^{\rho-1}\left(\frac{p_{b_{2, i}}}{p_{b_{1, i}}}\right)^{\sigma-1} \Phi_{i},
\end{aligned}
$$

intermediate input markets,

$$
\begin{aligned}
P_{i}(S) X_{i}(S) & =\varepsilon_{i}\left(1-\zeta_{i}\right) \Phi_{i}, \\
P_{i}(M) X_{i}(M) & =\left(1-\varepsilon_{i}\right)\left(1-\zeta_{i}\right) \Phi_{i} .
\end{aligned}
$$

and goods markets,

$$
\begin{aligned}
Y_{i}(M) & =C_{i}(M)+X_{i}(M), \\
Y_{i}(S) & =C_{i}(S)+X_{i}(S)+\delta_{i}(S) K_{i}(S), \\
Y_{i}(E) & =\delta_{i}(E) K_{i}(E),
\end{aligned}
$$

EK show that, with expontentially distributed productivities, the price indices for final goods are given by:

$$
P_{i}(j)=\gamma_{i}(j)\left\{\sum_{k=1}^{I}\left[\tau_{k n}(j) \frac{c_{k}}{A_{k}(j)}\right]^{-1 / \theta_{j}}\right\}^{-\theta_{j}}
$$


where $\gamma_{i}(j)=\left\{\Gamma\left(1+\theta_{j}\left[1-\eta_{i}(j)\right]\right)\right\}^{1 /\left[1-\eta_{i}(j)\right]}$ and $\Gamma$ is the Gamma function. Finally, the household optimality conditions in steady state are given by the Euler equations

$$
\begin{aligned}
& 1 / \beta=r_{i} / P_{i}(E)+1-\delta_{i}(E), \\
& 1 / \beta=v_{i} / P_{i}(S)+1-\delta_{i}(S),
\end{aligned}
$$

the intratemporal consumption equation

$$
P_{i}(M) C_{i}(M)=\frac{\phi}{1-\phi} P_{i}(S) C_{i}(S)
$$

and the budget constraint

$$
\begin{aligned}
w_{i} L_{i}+s_{i} H_{i}+v_{i} K_{i}(S)+r_{i} K_{i}(E)+N X_{i}= & P_{i}(M) C_{i}(M)+P_{i}(E) \delta_{i}(E) K_{i}(E) \\
& +P_{i}(S)\left[C_{i}(S)+\delta_{i}(S) K_{i}(S)\right]
\end{aligned}
$$

where $N X_{i}$ denotes net exports. Equations (13) - (26) characterize the steady-state equilibrium.

\section{A.3 Solving for Changes in the Skill Premium}

We conclude this section by showing that we can solve for changes in country $i$ 's skill premium using the following system of five equations:

$$
\begin{aligned}
\widetilde{r}_{i} & =\left[\widetilde{A}_{i}(S) / \widetilde{A}_{i}(E)\right] \widetilde{\pi}_{i i}(E)^{\theta_{E}} \\
\widetilde{s}_{i}^{\rho} / \widetilde{w}_{i}^{\sigma} & =\widetilde{p}_{b_{1, i}}^{\rho-\sigma}\left(\widetilde{L}_{i} / \widetilde{H}_{i}\right) \\
\widetilde{p}_{b_{1, i}} & =\left[\frac{1}{1+\xi_{i}^{H}} \widetilde{r}_{i}^{1-\rho}+\frac{\xi_{i}^{H}}{1+\xi_{i}^{H}} \widetilde{s}_{i}^{1-\rho}\right]^{1 /(1-\rho)} \\
\widetilde{p}_{b_{3, i}}^{1 / 1-\alpha_{i}} & =\left[\xi_{i}^{L} \widetilde{w}_{i}^{1-\sigma}+\left(1-\xi_{i}^{L}\right) \widetilde{p}_{b_{1, i}}^{1-\sigma}\right]^{1 /(1-\sigma)} \\
\widetilde{p}_{b_{3, i}} & =\widetilde{A}_{i}(S)^{\left(\varepsilon_{i}+\zeta_{i}-\varepsilon_{i} \zeta_{i}\right) / \zeta_{i}}\left[\widetilde{A}_{i}(M) / \widetilde{\pi}_{i i}(M)^{\theta_{M}}\right]^{\left(1-\varepsilon_{i}\right)\left(1-\zeta_{i}\right) / \zeta_{i}}
\end{aligned}
$$

where, $\widetilde{x} \equiv x^{\prime} / x$ denotes the ratio of a variable between the new and initial equilibrium, and where $\xi_{i}^{H}=\frac{s_{i} H_{i}}{r_{i} K_{i}(E)}$ and $\xi_{i}^{L}=\frac{w_{i} L_{i}}{w_{i} L_{i}+s_{i} H_{i}+r_{i} K_{i}(E)}$ denote relative factor shares in the initial equilibrium.

We proceed in order. By equations (6) and (22), we have

$$
P_{i}(j)=\gamma_{i}(j) c_{i} \pi_{i i}(j)^{\theta_{j}} / A_{i}(j)
$$

and taking changes between the new and initial equilibrium gives

$$
\widetilde{P}_{i}(j)=\widetilde{c}_{i} \tilde{\pi}_{i i}(j)^{\theta_{j}} / \widetilde{A}_{i}(j) .
$$

Similarly, by equation (25), we have

$$
\widetilde{r}_{i}=\widetilde{P}_{i}(E) .
$$


Equations (32) and (33) imply equation (27). By equations (14) and (16), we have

$$
\frac{s_{i}^{\rho}}{w_{i}^{\sigma}} \frac{H_{i}}{L_{i}}=\left(1-\lambda_{i}\right) \frac{1-\mu_{i}}{\mu_{i}} p_{b, i}^{\rho-\sigma} .
$$

Expressing the previous equation in changes gives equation (28). In addition, expressing the definition of $p_{b_{1, i}}$ in changes gives equation (29).

To obtain the remaining two equations, (30) and (31), we express the remaining marginal cost equations in changes:

$$
\begin{aligned}
\widetilde{c}_{i} & =\widetilde{p}_{b_{3, i}}^{\zeta_{i}} \widetilde{p}_{b_{4, i}}^{1-\zeta_{i}} \\
\widetilde{p}_{b_{4, i}} & =\widetilde{P}_{i}(S)^{\varepsilon_{i}} \widetilde{P}_{i}(M)^{1-\varepsilon_{i}} \\
\widetilde{p}_{b_{3, i}} & =\widetilde{v}_{i}^{\alpha_{i}} \widetilde{p}_{b_{2, i}}^{1-\alpha_{i}} \\
\widetilde{p}_{b_{2, i}} & =\left[\xi_{i}^{L} \widetilde{w}_{i}^{1-\sigma}+\left(1-\xi_{i}^{L}\right) \widetilde{p}_{b_{1, i}}^{1-\sigma}\right]^{1 / 1-\sigma}
\end{aligned}
$$

Letting $P_{i}(S)=1$ be the numeraire, equation (24) implies $\widetilde{v}_{i}=\widetilde{P}_{i}(S)=1$. Hence, equations (36) and (37) imply equation (30). Finally, by equation (32) and $\pi_{i i}(S)=1$, we have

$$
\widetilde{c}_{i}=\widetilde{A}_{i}(S)
$$

By equations (34), (35), and (38), we have

$$
\widetilde{A}_{i}(S)=\widetilde{p}_{b_{3, i}}^{\zeta_{i}} \tilde{p}_{b_{4, i}}^{1-\zeta_{i}}
$$

and

$$
\widetilde{p}_{b_{4, i}}=\widetilde{P}_{i}(M)^{1-\varepsilon_{i}}=\left\{\widetilde{A}_{i}(S) \widetilde{\pi}_{i i}(M)^{\theta_{M}} / \widetilde{A}_{i}(M)\right\}^{1-\varepsilon_{i}} .
$$

The two previous equations imply (31). Hence, we can solve for changes in country $i$ 's skill premium using equations (27)-(31).

\section{B Proofs}

In this section, we prove Proposition 1.

\section{B.1 Derivation of Equation (7)}

Here, we derive equation (7). By equations (14) and (16), we have

$$
\left(\frac{r_{i}}{s_{i}}\right)^{1-\rho}=\left[\frac{1-\lambda_{i}}{\lambda_{i}} \frac{K_{i}(E)}{H_{i}}\right]^{\frac{\rho-1}{\rho}}
$$


From the definition of $p_{b_{1, i}}$ and equation (39), we have

$$
\frac{p_{b_{1, i}}}{s_{i}}=\left(1-\lambda_{i}\right)^{-\frac{1}{\rho}}\left\{\lambda_{i}^{\frac{1}{\rho}}\left[\frac{K_{i}(E)}{H_{i}}\right]^{\frac{\rho-1}{\rho}}+\left(1-\lambda_{i}\right)^{\frac{1}{\rho}}\right\}^{\frac{1}{1-\rho}} .
$$

In addition, equations (14) and (16) imply

$$
\frac{s_{i}}{w_{i}}=\left(1-\lambda_{i}\right)^{\frac{1}{\sigma}}\left(\frac{1-\mu_{i}}{\mu_{i}}\right)^{\frac{1}{\sigma}}\left(\frac{p_{b, i}}{s_{i}}\right)^{\frac{\rho-\sigma}{\sigma}}\left(\frac{L_{i}}{H_{i}}\right)^{\frac{1}{\sigma}} .
$$

From equations (40) and (41), we obtain equation (7).

\section{B.2 Derivation of Equation (8)}

We now derive our first order approximation for the change in the skill premium. Let $\widehat{x} \equiv \log (\widetilde{x})$. Using this notation, we express equations (27), (28), and (31) as

$$
\begin{aligned}
\widehat{r}_{i} & =\widehat{A}_{i}(S)-\widehat{A}_{i}(E)+\theta_{E} \widehat{\pi}_{i i}(E) \\
\rho \widehat{s}_{i}-\sigma \widehat{w}_{i} & =(\rho-\sigma) \widehat{p}_{b_{1, i}}-\left(\widehat{H}_{i}-\widehat{L}_{i}\right) . \\
\widehat{p}_{b_{3, i}} & =\frac{\zeta_{i}+\varepsilon_{i}-\zeta_{i} \varepsilon_{i}}{\zeta_{i}} \widehat{A}_{i}(S)+\frac{\left(1-\zeta_{i}\right)\left(1-\varepsilon_{i}\right)}{\zeta_{i}}\left[\widehat{A}_{i}(M)-\theta_{M} \widehat{\pi}_{i i}(M)\right]
\end{aligned}
$$

Using the first-order approximation, $\exp (\widehat{x}) \approx 1+\widehat{x}$, we express equations $(30)$ and $(29)$ as

$$
\begin{aligned}
\widehat{p}_{b_{1, i}} & =\frac{1}{\left(1-\xi_{i}^{L}\right)} \frac{\widehat{p}_{b_{3, i}}}{\left(1-\alpha_{i}\right)}-\frac{\xi_{i}^{L}}{1-\xi_{i}^{L}} \widehat{w}_{i} \\
\widehat{p}_{b_{1, i}} & =\frac{1}{1+\xi_{i}^{H}} \widehat{r}_{i}+\frac{\xi_{i}^{H}}{1+\xi_{i}^{H}} \widehat{s}_{i}
\end{aligned}
$$

We now solve equations (42)-(46) for $\widehat{s}_{i}-\widehat{w}_{i}$. By equations (45) and (43), we have

$$
\widehat{s}_{i}=\frac{\rho-\sigma}{\rho} \frac{1}{\left(1-\xi_{i}^{L}\right)} \frac{\widehat{p}_{b_{3, i}}}{\left(1-\alpha_{i}\right)}+\left(\frac{\sigma}{\rho}-\frac{\rho-\sigma}{\rho} \frac{\xi_{i}^{L}}{1-\xi_{i}^{L}}\right) \widehat{w}_{i}-\frac{1}{\rho}\left(\widehat{H}_{i}-\widehat{L}_{i}\right),
$$

whereas by equations (45) and (46), we have

$$
\widehat{s}_{i}=\frac{1+\xi_{i}^{H}}{\xi_{i}^{H}\left(1-\xi_{i}^{L}\right)} \frac{\widehat{p}_{b_{3, i}}}{\left(1-\alpha_{i}\right)}-\frac{\xi_{i}^{L}\left(1+\xi_{i}^{H}\right)}{\left(1-\xi_{i}^{L}\right) \xi_{i}^{H}} \widehat{w}_{i}-\frac{1}{\xi_{i}^{H}} \widehat{r}_{i} .
$$

Equating the two previous expressions and solving for $\widehat{w}_{i}$, we have

$$
\widehat{w}_{i}=\frac{\rho+\sigma \xi_{i}^{H}}{\rho \xi_{i}^{L}+\sigma \xi_{i}^{H}} \frac{\widehat{p}_{b_{3, i}}}{\left(1-\alpha_{i}\right)}-\frac{\rho\left(1-\xi_{i}^{L}\right)}{\rho \xi_{i}^{L}+\sigma \xi_{i}^{H}} \widehat{r}_{i}+\frac{\left(1-\xi_{i}^{L}\right) \xi_{i}^{H}}{\rho \xi_{i}^{L}+\sigma \xi_{i}^{H}}\left(\widehat{H}_{i}-\widehat{L}_{i}\right),
$$


Equation (47) implies

$$
\widehat{s}_{i}-\widehat{w}_{i}=\frac{\sigma-\rho}{\rho} \frac{1}{1-\xi_{i}^{L}}\left[\widehat{w}_{i}-\frac{\widehat{p}_{b_{3, i}}}{\left(1-\alpha_{i}\right)}\right]-\frac{1}{\rho}\left(\widehat{H}_{i}-\widehat{L}_{i}\right)
$$

Equation (48) implies

$$
\widehat{w}_{i}-\frac{\widehat{p}_{b_{3, i}}}{1-\alpha_{i}}=\frac{\rho\left(1-\xi_{i}^{L}\right)}{\rho \xi_{i}^{L}+\sigma \xi_{i}^{H}}\left[\frac{\widehat{p}_{b_{3, i}}}{\left(1-\alpha_{i}\right)}-\widehat{r}_{i}+\xi_{i}^{H} \frac{1}{\rho}\left(\widehat{H}_{i}-\widehat{L}_{i}\right)\right] .
$$

By equations (49) and (50), we have

$$
\widehat{s}_{i}-\widehat{w}_{i}=\frac{\sigma-\rho}{\rho \xi_{i}^{L}+\sigma \xi_{i}^{H}}\left(\widehat{p}_{b_{2, i}}-\widehat{r}_{i}\right)-\frac{\xi_{i}^{H}+\xi_{i}^{L}}{\sigma \xi_{i}^{H}+\rho \xi_{i}^{L}}\left(\widehat{H}_{i}-\widehat{L}_{i}\right)
$$

Finally, by equations (42), (44), and (51), we have equation (8).

\section{Heterogeneous Sectors}

In this section, we extend the model to allow for heterogeneous production functions across sectors. In particular, we assume the production function is given by:

$$
y_{i}(\omega, j)=A_{i}(j) z_{i}(\omega, j) b_{3, i}^{\zeta_{j}} b_{4, i}^{1-\zeta_{j}}
$$

with

$$
\begin{aligned}
& b_{4, i}(j)=x_{S}^{\varepsilon_{j}} x_{M}^{1-\varepsilon_{j}}, \quad b_{2, i}(j)=\left[\mu_{j}^{1 / \sigma_{j}} l^{\left(\sigma_{j}-1\right) / \sigma_{j}}+\left(1-\mu_{j}\right)^{1 / \sigma_{j}} b_{1}^{\left(\sigma_{j}-1\right) / \sigma_{j}}\right]^{\sigma_{j} /\left(\sigma_{j}-1\right)}, \\
& b_{3, i}(j)=k_{S}^{\alpha_{j}} b_{2}^{1-\alpha_{j}}, \quad \text { and } b_{1, i}(j)=\left[\lambda_{j}^{1 / \rho_{j}} k_{E}^{\left(\rho_{j}-1\right) / \rho_{j}}+\left(1-\lambda_{j}\right)^{1 / \rho_{j}} h^{\left(\rho_{j}-1\right) / \rho_{j}}\right]^{\rho_{j} /\left(\rho_{j}-1\right)} .
\end{aligned}
$$

where we have dropped country-specific subscripts, $i$, from the production function parameters to facilitate exposition. The unit cost of production - for supplying the domestic market - of a producer with productivity $A_{i}(j) z_{i}(\omega, j)=1$ is now sector specific,

$$
c_{i}(j)=p_{b_{3, i}}^{\zeta_{j}}(j) p_{b_{4, i}}(j)^{1-\zeta_{j}} / \zeta_{j}^{\zeta_{j}}\left(1-\zeta_{j}\right)^{1-\zeta_{j}}
$$

where

$$
\begin{array}{ll}
p_{b_{4, i}}(j)=\frac{P_{i}(S)^{\varepsilon_{j}} P_{i}(M)^{1-\varepsilon_{j}}}{\varepsilon_{j}^{\varepsilon_{j}}\left(1-\varepsilon_{j}\right)^{1-\varepsilon_{j}}}, & p_{b_{2, i}}(j)=\left[\mu_{j} w_{i}^{1-\sigma_{j}}+\left(1-\mu_{j}\right) p_{b_{1, i}}(j)^{1-\sigma_{j}}\right]^{\frac{1}{1-\sigma_{j}}} \\
p_{b_{3, i}}(j)=\frac{v_{i}^{\alpha_{j}} p_{b_{2, i}}(j)^{1-\alpha_{j}}}{\alpha_{j}^{\alpha_{j}}\left(1-\alpha_{j}\right)^{1-\alpha_{j}}}, & \text { and } p_{b_{1, i}}(j)=\left[\lambda_{j} r_{i}^{1-\rho_{j}}+\left(1-\lambda_{j}\right) s_{i}^{1-\rho_{j}}\right]^{\frac{1}{1-\rho_{j}}}
\end{array}
$$


Integrating factor demands across producers, and adding across all destination countries $n$ and sectors $j$, we have equilibrium in factor markets,

$$
\begin{aligned}
v_{i} K_{i}(S) & =\sum_{j} \zeta_{j} \alpha_{j} \Phi_{i}(j) \\
w_{i} L_{i} & =\sum_{j} \zeta_{j} \mu_{j}\left(1-\alpha_{j}\right)\left[\frac{p_{b_{2, i}}(j)}{w_{i}}\right]^{\sigma_{j}-1} \Phi_{i}(j) \\
r_{i} K_{i}(E) & =\sum_{j} \zeta_{j} \lambda_{j}\left(1-\alpha_{j}\right)\left(1-\mu_{j}\right)\left[\frac{p_{b_{1, i}}(j)}{r_{i}}\right]^{\rho_{j}-1}\left[\frac{p_{b_{2, i}}(j)}{p_{b_{1, i}}(j)}\right]^{\sigma_{j}-1} \Phi_{i}(j) \\
s_{i} H_{i} & =\sum_{j} \zeta_{j}\left(1-\alpha_{j}\right)\left(1-\mu_{j}\right)\left(1-\lambda_{j}\right)\left[\frac{p_{b_{1, i}}(j)}{s_{i}}\right]^{\rho_{j}-1}\left[\frac{p_{b_{2, i}}(j)}{p_{b_{1, i}(j)}}\right]^{\sigma_{j}-1} \Phi_{i}(j)
\end{aligned}
$$

and intermediate input markets,

$$
\begin{aligned}
P_{i}(S) X_{i}(S) & =\sum_{j} \varepsilon_{j}\left(1-\zeta_{j}\right) \Phi_{i}(j) \\
P_{i}(M) X_{i}(M) & =\sum_{j}\left(1-\varepsilon_{j}\right)\left(1-\zeta_{j}\right) \Phi_{i}(j)
\end{aligned}
$$

where $\Phi_{i}(j) \equiv \sum_{n} \pi_{i n}(j) P_{n}(j) Y_{n}(j)$ denotes total revenue accruing to all country $i$ producers in sector $j$.

We now express the above conditions in terms of the factor content of trade. Define by $N X_{i}^{F}$ the units of factor $F$ that are embodied in county $i$ 's net exports,

$$
N X_{i}^{F}=\sum_{j=1}^{J} F_{i}(j) \omega_{i}(j)
$$

where $F_{i}(j)$ denotes the utilization of factor $F$ in country $i$ and sector $j$, and where $\omega_{i}(j)$ is the ratio of county $i$ 's net exports in sector $j$ to country $i$ 's total revenue in sector $j$,

$$
\omega_{i}(j)=\frac{\sum_{n}\left[\pi_{i n}(j) P_{n}(j) Y_{n}(j)-\pi_{n i}(j) P_{i}(j) Y_{i}(j)\right]}{\sum_{n} \pi_{i n}(j) P_{n}(j) Y_{n}(j)} .
$$

By equations (52) and (53), we have

$$
p_{F i} N X_{i}^{F}=\alpha_{F}(j) \sum_{n \neq i}\left[\pi_{i n}(j) P_{n}(j) Y_{n}(j)-\pi_{n i}(j) P_{i}(j) Y_{i}(j)\right],
$$

where $\alpha_{F}(j)$ denotes the share of sector $j$ revenue paid to factor $F$. By equation $(54)$ and $\pi_{i i}(j)=$ $\left[1-\sum_{n \neq i} \pi_{n i}(j)\right]$, we express equilibrium in the intermediate input markets as 


$$
\begin{aligned}
P_{i}(S) & =\frac{\sum_{j} \varepsilon_{j}\left(1-\zeta_{j}\right) P_{i}(j) Y_{i}(j)}{X_{i}(S)-N X_{i}^{X_{i}(S)}} \\
P_{i}(M) & =\frac{\sum_{j}\left(1-\varepsilon_{j}\right)\left(1-\zeta_{j}\right) P_{i}(j) Y_{i}(j)}{X_{i}(M)-N X_{i}^{X(M)}}
\end{aligned}
$$

and in the factor markets as

$$
\begin{aligned}
v_{i} & =\frac{\sum_{j} \zeta_{j} \alpha_{j} P_{i}(j) Y_{i}(j)}{K_{i}(S)-N X_{i}^{K(S)}} \\
w_{i} & =\frac{\sum_{j} \zeta_{j} \mu_{j}\left(1-\alpha_{j}\right)\left[\frac{p_{b_{2, i}}(j)}{w_{i}}\right]^{\sigma_{j}-1} P_{i}(j) Y_{i}(j)}{L_{i}-N X_{i}^{L}} \\
r_{i} & =\frac{\sum_{j} \zeta_{j} \lambda_{j}\left(1-\alpha_{j}\right)\left(1-\mu_{j}\right)\left[\frac{p_{b_{1, i}}(j)}{r_{i}}\right]^{\rho_{j}-1}\left[\frac{p_{b_{2, i}}(j)}{p_{b_{1, i}}(j)}\right]^{\sigma_{j}-1} P_{i}(j) Y_{i}(j)}{K_{i}(E)-N X_{i}^{K(E)}} \\
s_{i} & =\frac{\sum_{j} \zeta_{j}\left(1-\alpha_{j}\right)\left(1-\mu_{j}\right)\left(1-\lambda_{j}\right)\left[\frac{p_{b_{1, i}}(j)}{s_{i}}\right]^{\rho_{j}-1}\left[\frac{p_{b_{2, i}}(j)}{p_{b_{1, i}(j)}}\right]^{\sigma_{j}-1} P_{i}(j) Y_{i}(j)}{H_{i}-N X_{i}^{H}}
\end{aligned}
$$

Aggregate prices are:

$$
P_{i}(j)=\gamma_{i}(j) c_{i}(j) \pi_{i i}(j)^{\theta_{j}} / A_{i}(j)
$$

Equations (19)-(21), (23)-(26), and (55)-(61) yield a system of equations in $\left\{w_{i}, s_{i}, v_{i}, r_{i}\right\}_{i=1}^{I}$, $\left\{P_{i}(j)\right\}_{i=1, j \in \mathcal{J}}^{I},\left\{Y_{i}(j)\right\}_{i=1, j \in \mathcal{J}}^{I},\left\{K_{i}(E), K_{i}(S)\right\}_{i=1}^{I},\left\{C_{i}(M), C_{i}(S)\right\}_{i=1}^{I}$, and $\left\{X_{i}(M), X_{i}(S)\right\}_{i=1}^{I}$ that characterizes the steady-state equilibrium and that depends only on the sectoral domestic expenditure shares $\left\{\pi_{i i}(j)\right\}_{j \in \mathcal{J}}$, the sectoral domestic productivities $\left\{A_{i}(j)\right\}_{j \in \mathcal{J}}$, the factor content of trade for all factors $\left\{N X_{i}^{F}\right\}_{F \in \mathcal{F}}$, and the parameters $\left\{\zeta_{j}, \alpha_{j}, \mu_{j}, \lambda_{j}, \varepsilon_{j}, \sigma_{j}, \rho_{j}, \theta_{j}\right\}_{j \in \mathcal{J}}$.

\section{Data and Parameterization}

Domestic Expenditure Shares: For trade data, we define equipment trade as the sum of BEA industry codes 20-27 and 33. These codes are: Farm and Garden Machinery; Construction, Mining, etc.; Computer and Office Equipment; Other Nonelectric Machinery; Household Appliances; Household Audio and Video, etc.; Electronic Components; Other Electrical Machinery; and Instruments and Apparatus).

For gross output data, we define capital equipment goods as the sum of ISIC Rev. 3 codes 29-33. These codes are: Manufacture of machinery and equipment n.e.c.; Manufacture of office, accounting and computing machinery; Manufacture of electrical machinery and apparatus n.e.c.; Manufacture of radio, television and communication equipment and apparatus; and Manufacture of medical, precision and optical instruments, watches and clocks.

Dissaggregating capital payments into structures and equipment: For a given share of 
payments to capital in value added, i.e.

$$
\frac{v_{i} K_{i}(S)+r_{i} K_{i}(E)}{s_{i} H_{i}+w_{i} L_{i}+v_{i} K_{i}(S)+r_{i} K_{i}(E)}
$$

the parameter $\alpha_{i}$ determines the ratio of payments to capital structures relative to the payments to equipment capital, i.e. $v_{i} K_{i}(S) /\left[r_{i} K_{i}(E)\right]$. Given the difficulty of measuring capital rental rates, we construct them using the steady-state Euler equations for the accumulation of each type of capital,

$$
\begin{aligned}
1+R_{i} & =\frac{P_{i, t+1}(S) / P_{i, t+1}(C)}{P_{i, t}(S) / P_{i, t}(C)}\left\{1-\delta_{i}(S)+\frac{v_{i, t+1}}{P_{i, t+1}(S)}\right\} \\
& =\frac{P_{i, t+1}(E) / P_{i, t+1}(C)}{P_{i, t}(E) / P_{i, t}(C)}\left\{1-\delta_{i}(E)+\frac{r_{i, t+1}}{P_{i, t+1}(E)}\right\}
\end{aligned}
$$

where $R_{i}$ denotes the consumption-based real-interest rate and $P_{i, t}(C)$ denotes the price of the final consumption good in year $t$. Note that, in this calculation we allow for trends in relative prices (as above, introducing growth into our model does not change our results on the impact of trade on the skill premium).

To solve for the rental rates, we use data from NIPA for the 1963-2000 period. We define nonresidential equipment and software as the equipment sector $E$, and non-residential structures as the structure sector, $S$. We take $P_{i, t+1}(E) / P_{i, t}(E)$ and $P_{i, t+1}(S) / P_{i, t}(S)$ from NIPA's price indices for private investment (NIPA table 5.3.4). We use the GDP deflator from NIPA for $P_{i, t+1}(C) / P_{i, t}(C)$. We construct the annual depreciation rates of equipment and structures, $\delta_{i}(E)$ and $\delta_{i}(S)$, as the ratio of the current-cost depreciation (NIPA fixed assets table 4.4) to the current cost capital stock (NIPA fixed assets table 4.1) in these two sectors. We set the real interest rate $R_{i}$ to $4 \%$.

We use the 1963-2000 average of these variables and the Euler equations to obtain the relative return for equipment and structures $v_{i} / P_{i}(S) /\left[r_{i} / P_{i}(E)\right]$. We multiply this by the relative value of the capital stocks $\left[P_{i}(S) K_{i}(S) / P_{i}(E) K_{i}(E)\right]$ to obtain $v_{i} K_{i}(S) /\left[r_{i} K_{i}(E)\right]$. We use the 19632000 average current cost capital stock of non-residential equipment and non-residential structures (NIPA fixed assets table 4.1) for $P_{i}(E) K_{i}(E)$ and $P_{i}(S) K_{i}(S)$. Finally, to compute the share of payments to structures capital in value added, $\alpha$, we use the relative payments to structures and equipment and the share of payments to capital in value added (equal to one minus the average labor share, as defined in the body of the paper). We obtain a very similar value for $\alpha$ if we first calculate, year by year, the relative payments to equipment and structures and the share of capital, and then average these over time. 